\title{
Climate Change Shocks Exposure Index to Drought on the Livelihoods of the Smallholder Farmers in Kinakomba Ward, Tana River County, Kenya
}

\author{
Peter Ndegwa* Annie H. Ong'ayo Andrew W. Wamukota \\ Department of Environmental Studies-Community Development, Pwani University, P. Box 195, Kilifi
}

\begin{abstract}
Being susceptible to climate change means being unable to cope with the adverse effects of climate change especially droughts and a likelihood of experiencing harm due to its occurrence. The study sought to evaluate the effects of exposure to Climate related shocks on the livelihoods of the smallholder farmers with the intent of formulating appropriate policies to enable them cope with its impacts. A descriptive survey research design was used. Stratified random sampling was employed to select 390 households. Two methods were used to analyse exposure. Firstly the fuzzy logic in assessing susceptibility to drought involving a selection of input variables, Fuzzification, inference modelling and defuzzification and secondly DrinC Model software. The results revealed that the final value of the negative consequences of drought was 0.35 .The study also established a single index as 0.45 for exposure for the entire study period of 35 years for Kinakomba Ward .The study showed that exposure was statistically significant at $(0.000066)$. The study further revealed that the periods between occurrence of extreme droughts were reducing and at the same time that droughts were moving from being severe to being extreme within shorter periods of time leaving smallholder farmers who depend on rain fed agriculture with high exposures and risks as well as experiencing longer hunger periods with severe implications on their food and nutritional security for the vast populations in the study area. The Study concluded that the exposure to drought of the smallholder farmers in Kinakomba Ward is significantly related to their farming livelihood systems. This study recommends that the County Government in partnership with the National Government and other stakeholders develop a comprehensive disaster risk management framework to address the drought hazards and undertake mitigation and adaptation measures by equipping the smallholder farmers with knowledge on how to cope with the cyclic and vicious droughts' impacts that have led to serious irreversible harm to humans and livestock in the area.
\end{abstract}

Keywords: Exposure, Drought, Mitigation, Adaptation, Food security

DOI: $10.7176 /$ FSQM/94-07

Publication date: February $29^{\text {th }} 2020$

\section{Introduction}

To understand vulnerability to climate change, it is important to first understand exposure to climate change. The Intergovernmental Panel on Climate Change (IPCC) defines exposure as "the nature and degree to which a system is exposed to significant climate variations." Exposure is related to the climate stress level of a certain analysis unit or system (O'Brien et al. 2004), the risk and the nature and extent of change in climate variables. Exposure is also defined as those entities such as people, resources, infrastructures, goods, services or ecosystems exposed and prone to a natural hazard (Birkmann et al. 2011). Exposure may be represented as changes in long-term climate conditions or by changes in climate variability, including the magnitude and frequency of extreme events.

From the smallholder farmer perspective an analysis of vulnerability to climate change that address specific geographic location is needed at the local level so that the smallholders learn how to tackle climate change problems with precision Klein (2004). The external dimension of vulnerability refers to the exposure and risk to a certain phenomenon or stressors. According to Intergovernmental Panel on Climate Change (2001), vulnerability is a function of exposure, sensitivity and adaptive capacity. Mitigation and adaptation measures are needed to deal with exposure. IPCC (2007) defines Mitigation as the technological change and substitution that reduce resource inputs and emissions per unit of output. Although several social, economic and technological policies would produce an emission reduction, with respect to climate change, mitigation means implementing policies to reduce Green House Gases emissions and enhance sinks. Adaptation on the other hand refers to "the process of adjustment to actual or expected climate and its effects, in order to moderate harm or exploit beneficial opportunities" (IPCC 2012). So adaptation is an ongoing process which responds to actual or anticipated direct or indirect effects of climate variability and change (Dessai et al. 2009; Berkhout et al. 2006; Berkhout, 2012; Lavell et al. 2012). According to IPCC (2010) Adaptation also means those adjustments of a system that reduce vulnerability and increase the resilience to climate change.

Therefore, exposure is the essence and extent to which a set of procedures encounters socio-economic or environmental stress. In the context of drought, exposure has two sides namely the characteristics of hazards, such as changes in the frequency, intensity, magnitude, duration and the extent of drought. Thus, regions with increasing 
temperature and decreasing rainfall are identified as regions more exposed to drought. Because of Global warming, some regions in the world are likely to get wetter while those that are already under dry conditions likely to get drier. Thus, global warming is likely to increase drought occurrence and expansion of dry areas (IPCC 2013).

\section{Climate Extremes}

The earth's climate has changed over the last century. Increases in average temperatures have been observed around the globe and there is new and stronger evidence that most of the warming observed in the last 50 years is due to human activities (Field et al.2007). According to Agricultural Land Advisory Service (2009) climate change is a long-term shift in weather conditions identified by changes in temperature, precipitation, winds, and other indicators. Climate change can involve both changes in average conditions and changes in variability, including extreme events. Climate extremes such as droughts and floods are strongly influenced by both small and large scale weather patterns, modes of variability, land-atmosphere feedbacks and antecedent conditions (Ngaina and Mutai, 2013; IPCC 2013). There are many challenges in assessing changes in climate extremes not only because of the intrinsically rare nature of these events, but also because they disrupt conditions in key sectors like agriculture in many developing countries whose vulnerability to climate change has been exacerbated by its weak adaptive capacity (IPCC, 2007, 2013).Climate change has the potential to adversely affect the environment, communities and the economy unless action is taken now to reduce greenhouse gas emissions, bushfires and storm surges (Field et al. 2007).

Kenya is currently facing challenges arising from global phenomena, notable among them are global warming, crises. According to RoK (2011) the frequency of droughts and flash floods is expected to increase both in intensity and spread as a result of climate change. According to Gálya et al. (2017) drought is a complex phenomenon without an accepted definition. Drought is a natural phenomenon characterized by the reduction of available water over a substantial period of time due to reduced rainfall. The many definitions of drought can be clustered into four types namely meteorological, agricultural, hydrologic, and socioeconomic (Mishra and Singh 2016). Meteorological definitions look at drought on the basis of the degree of dryness and the duration of the dry period. The meteorological drought deals with precipitation and potential evapotranspiration Tigkas et al. 2015. Drought indices are important because they simplify complex climatic functions and quantify climatic severity, duration and frequency. They also communicate to the wider audience comprehensible information that can be used in the academic, strategic, and operational levels by a wider range of potential users (Tsakiris et al. 2007). Considering results from different drought indices leads to a comprehensive assessment of drought severity and a better perspective to specific research objectives (Tigkas et al. 2015) as they will negatively impact on crop and livestock enterprises in most areas for instance, Disease and pests associated with high temperatures due to drought are also likely to increase. Adaptation interventions that enhance farming communities' resilience to climate change induced effects are critical for the realization of the principle objectives of Food and National Security Policy (FNSP 2011).

Climate extremes affect food systems in several ways ranging from direct effects on crop production due to changes in rainfall leading to drought or flooding, or warmer or cooler temperatures leading to changes in the length of growing season, to changes in markets, food prices and supply chain infrastructure. The importance of climate extremes for food security differs from one region to another with southern Africa being affected most in food insecurity as it acts an underlying, ongoing issue and as a short-lived shock (Gregory et al. 2005).

With climate extremes, food will be produced under different adaptations to such change. The Conditions caused by the changes may be altered through initiatives from the food industry to mitigate against climate change or identify coping strategies (Boxall et al. 2009). The notion of coping has acquired a sizable and well developed literature. It describes the strategies used by those living with rapid onset disasters such as flash floods, and chronic disasters, including drought and food insecurity (Wisner et al. 2004). This matches well the dual interests of adaptation to climate extremes and baseline change. Coping has also been used to explore social change in relation to wider impacts of social violence and personal tragedy (Lee et al. 2009). Despite this wealth of knowledge of direct relevance to climate change adaptation, learning has been limited (Schipper and Pelling, 2006). Several coping models have been framed since 1970s like entitlements Sen (1981), human ecology Hewitt (1983), game theory Uphoff (1993) and livelihoods analysis (Leach et al. 1997) but the effect of climate extremes persists.

In this study the researcher focused on meteorological drought which is often looked at on the basis of the degree of dryness and the duration of the dry period. The aim of the study was to examine exposure to the drought phenomenon, calculate different drought indexes by identifying, monitoring and evaluating this phenomenon for a period that would enable the researcher to get results that could be used to recommend to policy makers ways of mitigating it. According to Peduzzi et al. (2009), drought exposure calculations are very complex and carry a high uncertainty.

The objective of the study was to evaluate the effects of exposure to Climate related shocks on the livelihoods of the small holder farmers in Kinakomba Ward. The study was also guided by the following null hypothesis: $H_{01}$ The exposure to drought of the smallholder farmers in Kinakomba Ward is Not significantly related to their 
farming livelihood systems

\subsection{Theoretical Framework}

This study used the Social Ecological Systems (SESs) theoretical framework initially proposed by Ostrom (2007). It was built to provide common vocabulary and logical linguistic structure to facilitate understanding of the sustainability of SESs. According to Ostrom (2005) a Framework provides the basic vocabulary of concepts and terms used to construct explanations of a theory.

The theory is very useful in managing ecosystems and finding solutions for environmental problems. It helps to understand the key elements of the structure of a system (Levin et al. 2013), however Levin et al. (2013) say that the concept of SES is challenging to implement in management and policy because they require the understanding of multiple approaches and are thus too complex to model. The long term goal of this framework is increase general knowledge of SES through the study of multiple individual cases in the context of solving environmental challenges, including nonlinearity, scale issues, heterogeneity, risk and uncertainty (Ostrom 2007, 2009; Hinkel et al. 2015).

On the other hand a model constitutes a manifestation of a theoretical explanation of the functional relationships among independent and dependent variables important in a particular setting (McGinnis \& Ostrom 2014). The SES framework is designed to identify basic working parts and their relationships to one another. According to McGinnis and Ostrom (2014) the SES framework is an ontology, in the sense that it defines a language of terms and specifies a series of logical relationships among these terms. Thus the SES framework offers knowledge relevant to diagnosis of properties of specific SESs to different situations.

\subsection{Conceptual Framework}

This theoretical framework was conceptualized for indicators focusing on the vulnerability of the smallholder farmers in Kinakomba Ward SESs. In Kinakomba Ward the drought hazard was assessed. In this work the Resource System (RS) is the smallholder farming sector and the Resource Units (RU) are the resources harvested by the smallholder farmers. The Governance System (GS) includes characteristics pertaining to the national and ounty governments and factors shaping rules and governance arrangement in Kenya. These determine incentives and behaviour for Actors (A) involved in the agricultural sector. These are the smallholder farmers, nongovernmental organizations, government officials and researchers. The social, economic, and political setting(S) is in the Kinakomba Ward context, in Tana River County. The nature and magnitude of drought as well as the vulnerability of the SES determines the impacts experienced by the SES (community) and its sub-systems and also the risk to experience harm (Sebesvari et al. 2016). Hazards might originate within a given SES or could be generated outside an SES. According to Sebesvari et al. (2016) these interactions from outside and SES internal processes might lead to transformations and tipping processes which greatly influence the vulnerability context. This conceptual SES framework aims to synthesize the Exposure index on the socioeconomic characteristics of the smallholder farmers in Kinakomba Ward for the social system.

The theoretical framework is conceptualized as shown in figure 1.0 below:

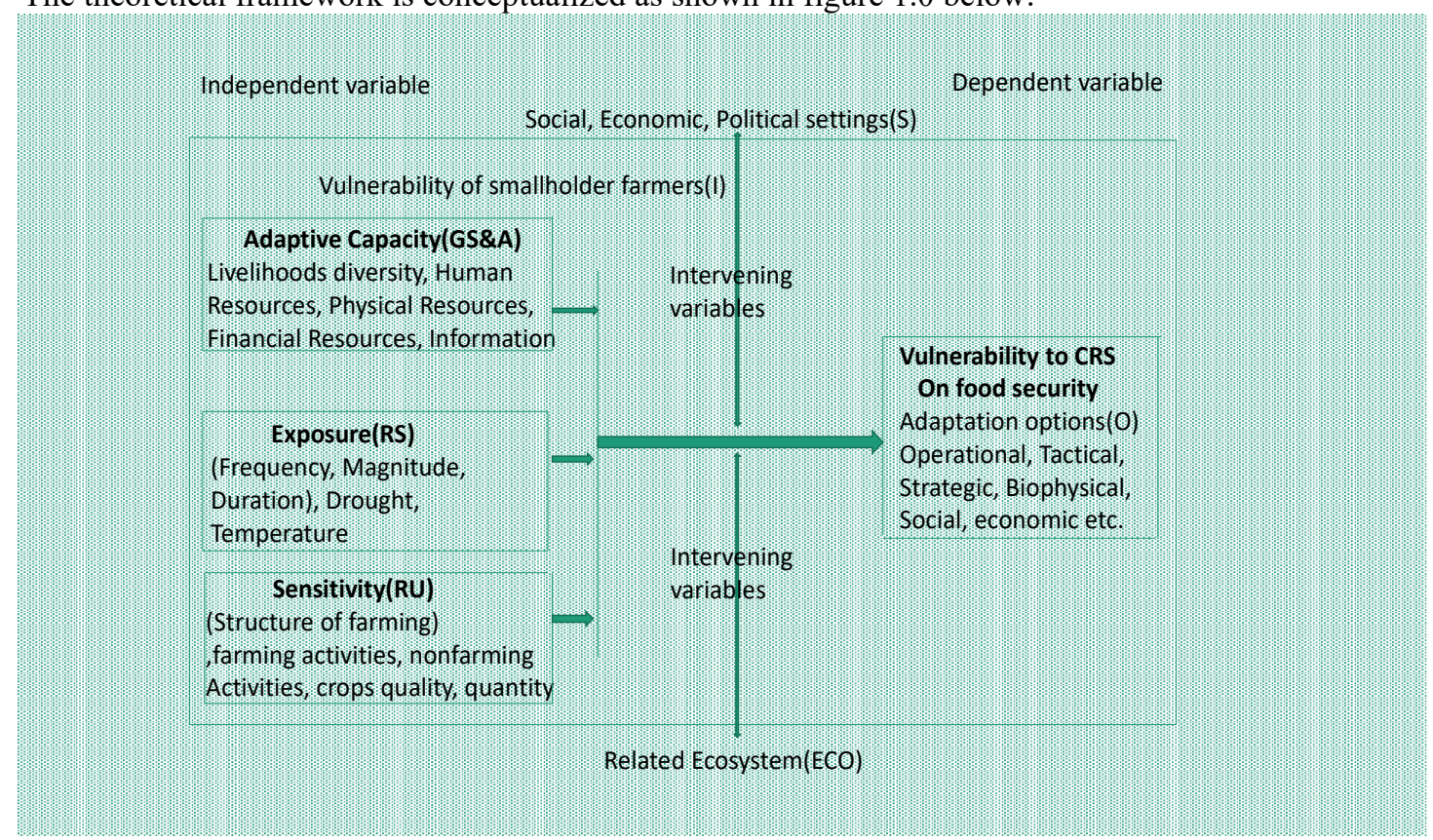

Figure 1 The conceptual framework 
The Three boxes for independent variable denote first-tier categories RS, RU, GS, and A are the highest-tier variables that contain multiple variables. The main box containing the interior elements of the figure indicates that the focal SES is a logical whole, but that exogenous influences from related ecological systems (ECO) and socialeconomic-political settings (S) can affect any component of the SES. These exogenous influences might emerge from the dynamic operation of processes at larger or smaller scales than that of the focal SES. The use of this framework is in three steps as suggested by McGinnis and Ostrom (2014). First step is selection of a focal situation of analysis in Kinakomba Ward where the components of the vulnerability system identified and how they are interacting. Second is identification of the potential variables and their indicators namely as vulnerability is a function of exposure, sensitivities and adaptive capacity. The third step is the analysis of the interactions of these variables and communication and dissemination of the results that were obtained for all the variables. Thus this framework facilitated exchange of knowledge acquired at the end of this process in this case of Exposure Index from the entire framework.

\section{Research Methodology}

\subsection{Research Design}

The study adopted a descriptive research design which allows collection of information about people's attitudes, opinions or habits (Kombo and Tromp, 2006). Kothari (2004) recommended descriptive design as it allows the researcher to describe, record, analyze and report conditions that exist or existed.

\subsection{Study area}

The study took place in Kinakomba Ward, Galole Sub-County of Tana River County. Tana River County is subdivided into three Sub-Counties of Bura, Galole and Garsen with a total area of 35,375.8 $\mathrm{KM}^{2}(13,658.7 \mathrm{sq}$. miles) whereby Trust land forms the bigger portion of the County with over $90 \%$ of the land. Galole Sub-County has four Wards of Wayu, Chewani, Mikinduni and Kinakomba. Kinakomba Ward is 556.9 square KM with 5 locations and 11 sub locations.

Kinakomba Ward has a population of about 18,000 people $(3908 \mathrm{HH})$ which is about $7 \%$ of the total population of the whole County. The Ward as a whole falls within the Coast low land climatic Zone $\mathrm{CL}_{3}, \mathrm{CL}_{4}$ and $\mathrm{CL}_{5}$. These zones are characterized by scarce rainfall ranging between $300 \mathrm{~m}-600 \mathrm{~mm}$ per annum only. The rainfall is erratic and unreliable resulting in persistent moisture stress in the soil profile. It is characterised by a flood plain along the banks of river Tana prone to flooding whenever the river bursts its banks. Apart from river floods the area is also sometimes affected by floods from the hinterland through seasonal rivers. The community lives in the floods plain and cultivate on the river banks making them very vulnerable to flash floods disasters because they have left the ground bare and the river banks are eroding at an alarming rate causing the river to change its course in many places frequently. The floods disasters experienced in Kinakomba Ward are on annual basis causing untold suffering, displacement of households and death of livestock. Being also in a Semi-Arid Area the community is confronted by immanent, persistent and prolonged droughts every second year and the frequency is increasing fast. The weather condition exhibits very high evaporation demand. From wood-head maps, the average evapo-transpiration during the dry and sunny months with a crop factor of 0.9 , is $5.2 \mathrm{~mm} /$ day CIDP II, (2018-2022). Average annual temperatures are about $30^{\circ} \mathrm{C}$ with the highest being $41^{\circ} \mathrm{C}$ around January-March and the lowest being $20.6^{\circ} \mathrm{C}$ around June-July. The area is between $70-100 \mathrm{~m}$ above sea level. Slopes are within the range of $0.05 \%-0.15 \%$ with local surface undulations. The soils range from sandy, dark clay and sandy loam to alluvial deposits. The soils are deep around the riverine environments but highly susceptible to erosion by water and wind. Soils in the hinterlands are shallow and have undergone seasons of trampling by livestock, thus are easily eroded during rainy seasons CIDP II, (2018-2022). The vegetation ranges from scrubland to thorny thickets within the riverine area. Main crops grown are mangoes, bananas, maize, green grams, cowpeas, tomatoes, vegetables and melons while main livestock kept are cattle, sheep and goats. The study site is as shown in Figure 2 above. 


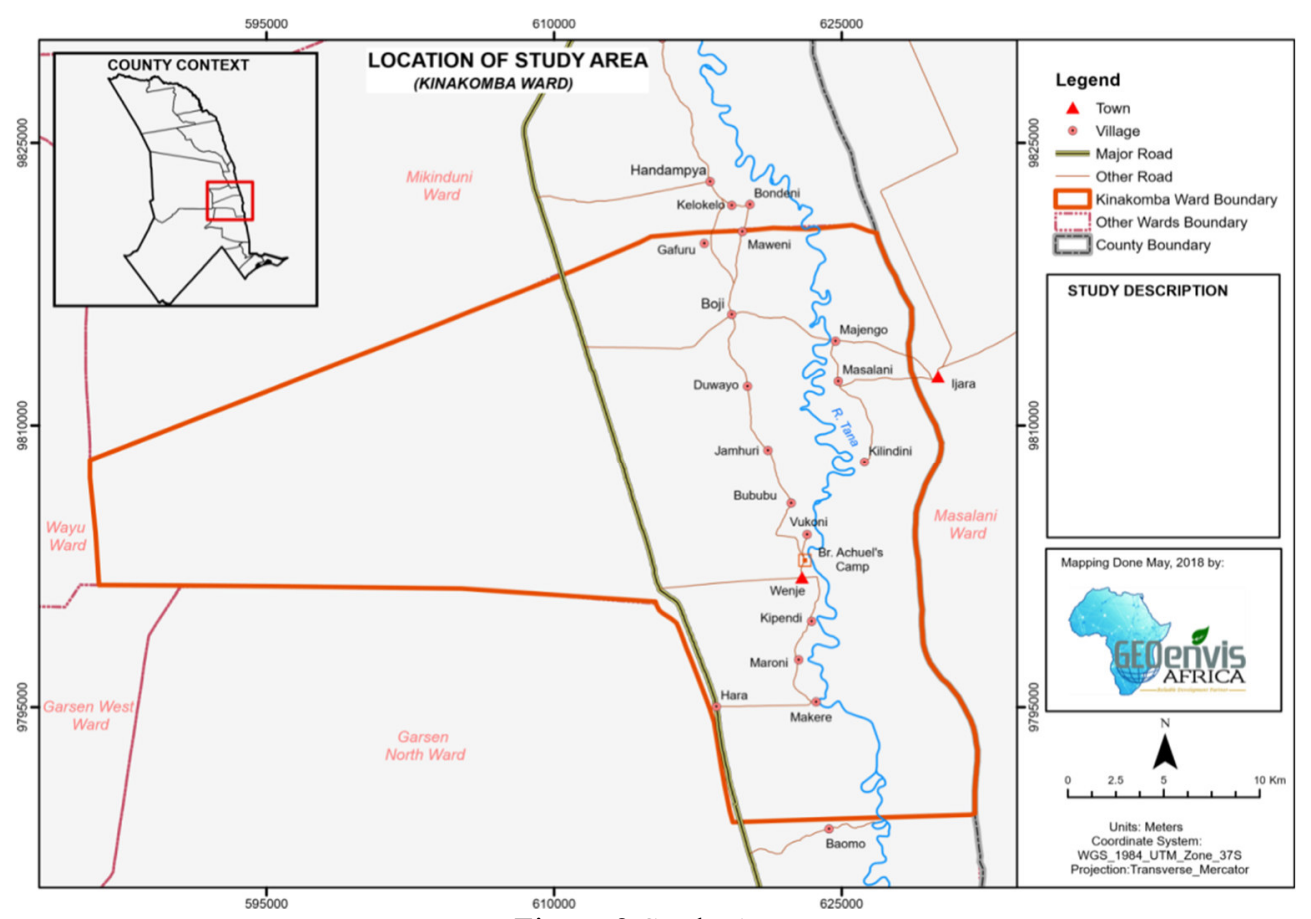

Figure 2 Study Area

\subsection{Sample size and sampling procedure}

A sample of the study sample 390 households from accessible population of 3,920 households who are subjected to climate change shocks in Kinakomba Ward. A sample size of $10 \%-30 \%$ of the accessible population is adequate to serve as a study sample (Mugenda and Mugenda, 2005). Multi-stage random sampling procedure was used to select the sample. First random sampling was used to select Kinakomba Ward out of the fifteen administrative Wards in Tana River County. The selected Kinakomba Ward has five administrative Locations which are Gwano, Jamhuri, Kinakomba, Ndura and Mazuni. In the second stage the researcher selected eleven Sub-Location areas (ESLs) from each of the Locations. The ESLs that were Hara, Maroni and Wenje from Gwano Location, Bububu from Jamhuri Location, Majengo and Masalani from Kinakomba Location, Gafuru, Mazuni and Mkomani from Mazuni Location and Bondeni and Handampia from Ndura Location. The Sample frame was obtained by listing the villages under each of the ESLs from where samples were taken. The strata was based on the smallholder farmers in the listed village. Stratified random sampling was used to sample households to participate in the study. The $10 \%$ of the households sampled was proportionately distributed in the strata and calculated as shown in Table 1.0 .

Table 1.0 Sample Frame

\begin{tabular}{|l|l|l|}
\hline Location & Number of households & $10 \%$ of accessible \\
\hline Gwano & $\mathbf{9 5 2}$ & $\mathbf{9 5}$ \\
\hline Hara & 322 & 32 \\
\hline Maroni & 229 & 23 \\
\hline Wenje & 405 & 41 \\
\hline Jamhuri & $\mathbf{6 5 4}$ & $\mathbf{6 5}$ \\
\hline Bububu & 654 & 65 \\
\hline Kinakomba & $\mathbf{9 1 2}$ & $\mathbf{9 1}$ \\
\hline Majengo & 614 & 61 \\
\hline Masalani & 297 & 30 \\
\hline Mazuni & $\mathbf{5 4 2}$ & $\mathbf{5 4}$ \\
\hline Gafuru & 256 & 26 \\
\hline Mazuni & 128 & 13 \\
\hline Mkomani & 159 & 16 \\
\hline Ndura & $\mathbf{8 4 2}$ & $\mathbf{8 4}$ \\
\hline Bondeni & 492 & 49 \\
\hline Handampia & 352 & 35 \\
\hline Total & $\mathbf{3 9 0 2}$ & $\mathbf{3 8 9}$ \\
\hline
\end{tabular}


Households were selected by firstly using 10 landmarks i.e. Mosque, Church, Shop, school, Village water point, Posho mill, Village meeting baraza park, junction, electricity pole and Chief's camp and then from each point visiting households until 6 to 10 completed interviews were achieved. At the household level, the interview was with the head or spouse ensuring adequate representation of women.

\subsection{Data Collection Instruments}

\subsubsection{Questionnaire}

Three sets of questionnaires and an observation checklist were used to collect data. The questionnaires were administered to the respondents. The questionnaire for the smallholder farmers had two sections

Structured and semi structured .One part was covering the selection of input variables and Fuzzification including questions on Consequences when drought occurs in the study area. Then other questions were on Climate Change including Historical setting on temperatures and precipitation of the area.

Semi structured questions assisted in generating in-depth and explanatory qualitative information. This method allowed flexibility, follow up to original questions and pursuing of new lines of questioning, two-way interaction and facilitated exchange of information between the interviewer and interviewee making the atmosphere more relaxed. The use of both questionnaires and semi-structured questions is necessary in order to get as much information as possible from the community members. Administration of questionnaire to Key informants was done with people with vast experience and knowledge who can provide extensive insight into biosocio-cultural aspects of the community. Observation overcomes one of the key disadvantages of interviews and questionnaires that is, that the responses provided may not be accurate (Dawson 2009).

Focus Group Discussions was developed and used to collect information on Exposure. The tool allowed for in-depth probing while the observation schedule was prepared and shared. This involved transect walks across the village and interacting with the villagers freely. This gave the feeling of the situation as is on the ground.

\subsection{Use of DrinC Model for Data analysis}

During the focus group discussions with the community, the respondents brought a historical aspect into the conversation on how temperatures and precipitation had affected them. They also expressed how they coped in times of extreme drought. This led the researcher to investigate more and sought more information from the Meteorological Department on the authenticity of the claims of the community. The researcher sought for the Meteorological data on precipitation, temperatures, relative humidity and evapotranspiration for the past 35 years for the Kinakomba Ward and the surrounding areas that is from Garissa to Garsen. The data was from the Station ID 9039000, the Garissa Meteorological Station.

The researcher used the software for measuring drought known as DrinC (Drought Indices Calculator). He calculated the Reconnaissance Drought Index (RDI), the Streamflow Drought Index (SDI), the Standardised Precipitation Index (SPI) and the Precipitation Deciles (PD), (Tigkas et al. 2015). Tigkas et al. (2015) state that the drought ends when: (i) the precipitation measured during the past month already places the 3-month total in or above the fourth decile, or (ii) the precipitation total for the past 3 months is in or above the eighth decile.

The researcher calculated Reconnaissance drought index (RDI) which is developed to approach the water deficit in a more accurate way, as a sort of balance between input and output in a water system (Tsakiris and Vangelis 2005; Tsakiris et al. 2007c). The calculations were based both on cumulative precipitation (P) and potential evapotranspiration (PET), which were one measured (P) and one calculated (PET) determinant. Positive values of RDIst indicated wet periods, while negative values indicated dry periods compared with the normal conditions of the area. The researcher also calculated Standardized precipitation index (SPI) where the long-term precipitation record for the 35 years were fitted to a probability distribution, which was then transformed into a normal distribution so that the mean SPI for Kinakomba Ward and desired period was zero (McKee et al. 1993; Edwards and McKee 1997). Positive SPI values indicated greater than median precipitation, and negative values indicated less than median precipitation. Since SPI was normalised, wetter and drier climates were represented in the same way. The researcher then calculated Precipitation Deciles which was a meteorological drought indices method introduced by Gibbs and Maher (1967). The precipitation totals for the preceding 3 months were ranked against climatologic records and when the sum fell within the lowest decile of the historical distribution of 3month totals, then Kinakomba Ward was considered to be under drought conditions (Kininmonth et al . 2000). The drought ended in two ways first when the precipitation measured during the past month already placed the 3month total in or above the fourth decile, and secondly when the precipitation total for the past 3 months was in or above the eighth decile. The results for each drought index are presented per year thus allowing a direct comparison of drought severity for the 35 years under review.

\subsection{Validity and Reliability of Research Instruments}

The validation of the instruments were determined before being used for data collection in the field. This reduced biasness of the data collected (Abbott \&Bordens 2011). This was done by experts from the department of 
Environmental Studies- Community Development of Pwani University, to assess the face, content and construct validity of the instrument. A pilot study was done prior to collection of data to test the reliability of the instruments. Reliability of the instruments was determined through a piloting testing. A test-retest technique was used to, using 39 households which make 10 percent of the study sample. According to Orodho (2004) the number in the pretest should be at least 10 percent of the entire sample. Cronbach's alpha was used to determine the internal consistency of items in the questionnaire to gauge its reliability. According to Cronbach (1957) a coefficient of between $0.7 \leq \alpha<0.9$ is taken to be good enough while that of $\alpha \geq 0.9$ is taken to be excellent George (2003).

\subsection{Measuring Exposure by Fuzzification Method}

Respondents were asked the following questions; when there is drought will you have enough food to eat, drinking water or little rain. Will your farms be able to yield any harvests, will you be forced to burn charcoal more often, will you be forced to seek food aid from government and NGOs, will you be forced to leave your home or will you become ill more often. The researcher assessed the susceptibility to drought by finding out the indicators to quantify and measured susceptibility by finding out, how these indicators are interpreted, how the relationship between different factors for susceptibility are described and quantitatively modelled and how a single numerical index is computed for comparing susceptibility between different villages to establish exposure.

This was achieved by asking the respondents to appraise eight classes of possible consequences of drought which led to a four step methodology according to (Acosta-Michlik et al. 2008; Kro“mker et al. 2008) and Ta"nzler and Carius, (2008) as follows: i) Selection of input variables, ii) Fuzzification, iii) Inference modelling and iv) Defuzzification (Bothe 1998, Aliev et al. 2000)

2.7.1 Selection of input variables.

The researcher using the data collected on the indicators analyzed the variables according to how different respondents had responded. The researcher used Fuzzification to analyse the data.

\subsubsection{Fuzzification}

Fuzzification according to Alcamo et al. (2008) is the translation from numerical data to linguistic categories and is accomplished through membership functions which define the degree of membership of each indicator in each category. The indicators of drought were analysed using Fuzzification. The researcher created membership functions to quantify linguistic terms and represented a fuzzy set graphically. Different levels of drought were translated with the help of three different membership functions one for each category of "Likely", "Partly likely and partly unlikely" and "Likely". A membership function for a fuzzy set A on the universe of discourse X is defined as $\mu \mathrm{A}: \mathrm{X} \rightarrow[0,1]$. So each element of $\mathrm{X}$ is mapped to a value between 0 and 1 . This membership value quantifies the degree of membership of the element in $\mathrm{X}$ to the fuzzy set $\mathrm{A}$. Thus $\mathbf{x}$ axis represents the universe of discourse while $\mathbf{y}$ axis represents the degrees of membership in the $[0,1]$ interval. In the questionnaire the researcher asked the participants to rate each of the 8 consequences of drought according to: $1=$ 'likely', $0=$ 'partly likely and partly unlikely', -1 = 'unlikely'. Then the sum of the different consequences were used to define the membership functions.

\subsection{Inference modelling}

To quantify susceptibility an inference model consisting of a rule system made up of linguistic statements of the variables described by the fuzzy logic was constructed according to Kro"mker et al. (2008), (Roberts, 1996), Wu et al. (1996), Silvert (2000), Mackay and Robinson (2000) and Kangas and Kangas (2004). This system defines the relationship between a given combination of indicators and a rule is needed for all variables and all their categories.

Step 1: Construct knowledge base rules

When having two variables $\mathrm{A}$ and $\mathrm{B}$ each having two categories then four rules are needed to describe the resulting variable $\mathrm{C}$ as follows:

Rule 1: If $\mathrm{A}$ is low and $\mathrm{B}$ is low, then $\mathrm{C}$ is low

Rule 2: If $\mathrm{A}$ is high and $\mathrm{B}$ is high, then $\mathrm{C}$ is high

Rule 3: If $\mathrm{A}$ is low and $\mathrm{B}$ is high, then $\mathrm{C}$ is medium

Rule 4: If $\mathrm{A}$ is high and $\mathrm{B}$ is low, then $\mathrm{C}$ is medium

From the questionnaire the researcher got data to derive membership functions for the eight categories of the indicator of Negative consequences of drought. The researcher asked the participants to appraise eight classes of possible negative consequences of drought.

Step 2: Obtain fuzzy value

Fuzzy set operations perform evaluation of rules. The researcher fuzzified each indicator through 3 membership functions using rule system with nine rules. This brought about 4 sub-dimensions each being a product of two indicators using defuzzification via 4 membership functions. Then through Fuzzification with 4 membership functions the researcher came up with two main dimensions from the four and below is shown how this was arrived at. 


\subsubsection{Defuzzification (Bothe 1998; Aliev et al. 2000)}

Since the inference model is based on fuzzy logic, the outputs of the model are fuzzy estimates and to combine all the results the researcher performed the defuzzification process.

2.7.5 Hypothesis Testing (Lehmann et al. 2005)

Then the researcher tested the hypothesis. The chi-square goodness of fit test was applied because there was one categorical variable from a single population. It was used to determine whether sample data were consistent with the hypothesized distribution.

It was appropriate to use the chi-square goodness of fit test because, the sampling method was simple random sampling, the variable under the study was categorical and the expected value of the number of sample observations in each level of the variable was at least 5. The researcher used 4 stages: Stated the hypotheses, Formulated an analysis plan, Analyzed sample data, and then interpreted results.

Stage 1: The researcher stated the Hypotheses

The researcher stated the null hypothesis $\left(\mathrm{H}_{0}\right)$ and an alternative hypothesis $\left(\mathrm{H}_{\mathrm{a}}\right)$. The hypotheses were stated in such a way that they were mutually exclusive. That is, if one was true, the other had to be false; and vice versa.

i. $\mathrm{H}_{02}$ The exposure to drought of the smallholder farmers in Kinakomba Ward is Not significantly related to their farming livelihood systems

ii. $\mathrm{H}_{\mathrm{al}}$ : The exposure to drought of the smallholder farmers in Kinakomba Ward is significantly related to their farming livelihood systems. Note that for the null hypothesis to be rejected at least one of the specified proportions is not true.

Stage 2: The researcher formulated an Analysis Plan

This analysis plan described how to use sample data to accept or reject the null hypothesis.

1. Significance Level here the researcher used was equal to 0.01

2. The test Method. The researcher used the Chi-square goodness of fit test to determine whether observed sample frequencies differed significantly from expected frequencies specified in the null hypothesis.

Stage 3: The researcher Analyzed Sample Data

By using sample data the researcher was looking for the degrees of freedom, expected frequency counts, test statistic, and the P-value associated with the test statistic.

\section{Results and Discussion}

The researcher assessed exposure in the study area by evaluating the influence of Climate Change patterns on the livelihoods of the smallholder farmers in Kinakomba Ward. Respondents were asked questions related to climate change which included the understanding of what climate change meant to the respondents, what mode of access for information on hazards and livelihood shocks in the area, the common climate resilience practices in the area and the early warning signs of drought.

\subsection{Climate Change}

Majority $(100 \%)$ of the respondents in the study when asked what they understood by climate change indicated different weather patterns, drought and erratic rains as shown in the table below.

Table 1 understanding of climate change

\begin{tabular}{|ll|r|r|}
\hline & & Frequency & Valid Percent \\
\hline Valid & $\begin{array}{l}\text { different weather patterns, } \\
\text { drought, erratic rains }\end{array}$ & 390 & 100.0 \\
\hline
\end{tabular}

When asked to indicate the common climate resilient practices that they use in their area majority $(90.5 \%)$ indicated irrigation.

Table 2 common resilient practices

\begin{tabular}{|ll|r|r|}
\hline & & Frequency & Valid Percent \\
\hline \multirow{3}{*}{ Valid } & floods receded & 37 & 9.5 \\
& irrigation & 353 & 90.5 \\
& Total & 390 & 100.0 \\
\hline
\end{tabular}

When asked what are the early warning signs of drought in their area majority (52.3\%) indicated these as hot sun, strong winds and animal behaviour while $40.8 \%$ indicated hot sun and strong winds and $6.9 \%$ indicated these as strong winds only. 


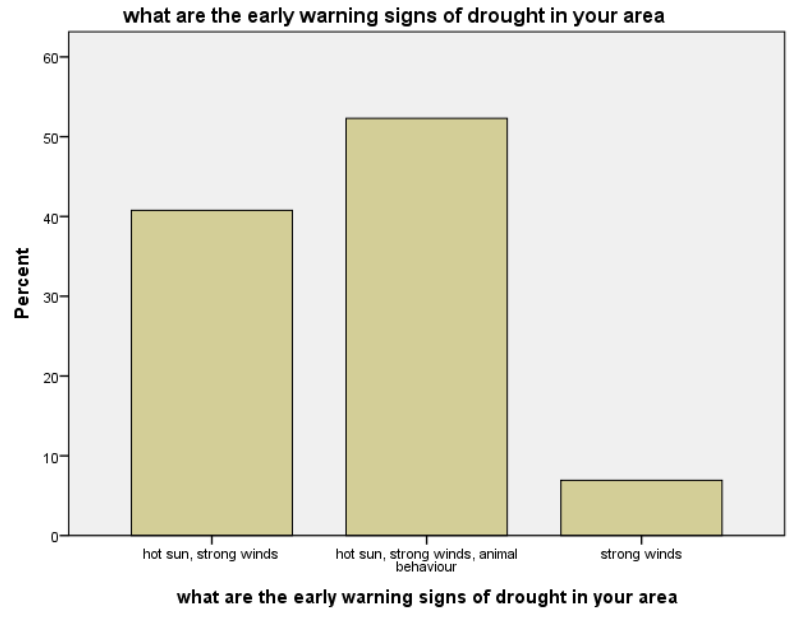

Figure 3 The early warning signs

3.2 Measuring exposure using fuzzy methodology.

The researcher sought to know the Consequences when drought occurs on;

3.2.1 Food availability during drought

The respondents were asked when there is drought if they will have enough food and majority $(47.7 \%)$ said it was unlikely while $46.7 \%$ said it was likely and $5.6 \%$ said it was partly likely and partly unlikely.

When there is drought we will not have enough food to eat

Table 4 food availability during drought

\begin{tabular}{|ll|l|l|}
\hline & & Frequency & Valid Percent \\
\hline Valid & likely & 182 & 46.7 \\
& partly likely and & 22 & 5.6 \\
part unlikely & & \\
unlikely & 186 & 47.7 \\
Total & 390 & 100.0 \\
& & & \\
\hline
\end{tabular}

On availability of rains the respondents all (100\%) said that it was likely.

We will have little or no rains at all

\begin{tabular}{|c|c|c|c|}
\hline & & Frequency & Valid Percent \\
\hline Valid & likely & 390 & 100.0 \\
\hline
\end{tabular}

Respondents were asked if their farms will produce harvest during drought majority $47.7 \%$ said it was unlikely while $38.7 \%$ said it was likely and $13.6 \%$ said it was partly likely and partly unlikely.

On charcoal burning the respondents were asked if when there is drought they will be forced to burn charcoal more often and majority $86.4 \%$ said that was partly likely and partly unlikely while only $13.6 \%$ said that was likely. We will be forced to burn charcoal more often

Table 6 On charcoal burning

\begin{tabular}{|ll|l|l|}
\hline \multicolumn{2}{|c|}{} & Frequency & Valid Percent \\
\hline Valid & likely & 53 & 13.6 \\
& $\begin{array}{l}\text { partly likely and partly } \\
\text { unlikely }\end{array}$ & 337 & 86.4 \\
& Total & 390 & 100.0 \\
& & \\
\hline
\end{tabular}

When asked if they will be forced to seek food aid in case of drought majority $44.4 \%$ said that was likely while $41.8 \%$ said it was unlikely and $13.8 \%$ said it was partly likely and partly unlikely.

We will be forced to seek food aid from the government and Non-Governmental Organizations 
Table 6 On seeking food aid

\begin{tabular}{|ll|l|l|}
\hline & Frequency & Valid Percent \\
\hline Valid & likely & 173 & 44.4 \\
& partly likely and partly & 54 & 13.8 \\
& unlikely & 163 & 41.8 \\
unlikely & 390 & 100.0 \\
Total & & \\
\hline
\end{tabular}

\subsubsection{Availability of drinking water during drought}

Respondents were asked if there will be enough drinking water during drought and majority $100 \%$ said this was unlikely. When asked on leaving their homes in case of drought majority $52.3 \%$ said that was partly likely while $47.7 \%$ said it was unlikely. When asked if they will become ill more often in case of drought majority $52.3 \%$ said it was partly likely and partly unlikely while $47.7 \%$ said it was unlikely.

We will not have enough drinking water

Table 7 On availability of water

\begin{tabular}{|l|l|l|}
\hline & Frequency & Valid Percent \\
\hline Valid unlikely & 390 & 100.0 \\
\hline
\end{tabular}

We will be forced to leave our home

Table 8 On leaving home because of drought

\begin{tabular}{|ll|l|l|}
\hline & Frequency & Valid Percent \\
\hline Valid & partly likely and partly & 204 & 52.3 \\
& unlikely & 186 & 47.7 \\
& unlikely & 390 & 100.0 \\
Total & & \\
\hline
\end{tabular}

We will become ill more often

Table 9 On being ill because of drought

\begin{tabular}{|ll|l|l|}
\hline & Frequency & Valid Percent \\
\hline Valid & partly likely and partly & 204 & 52.3 \\
& unlikely & 186 & 47.7 \\
unlikely & 390 & 100.0 \\
Total & & \\
\hline
\end{tabular}

\subsection{Defuzzification (Bothe 1998; Aliev et al. 2000) Results;}

From the defuzzification process the results showed that variable A had a membership of 0.4 for low and 0.35 for high and variable B had 0.35 for high and 0.32 for low. So four rules of inference came into play. The researcher chose the AND-conditions meaning the mathematically appropriate set operation was intersection, computed as the minimum of two membership value. The researcher chose the defuzzification technique called Center of gravity (Eierdanz et al. 2008). To obtain a final estimate of susceptibility, the Centre of gravity of the joined areas of all output variables were calculated and projected onto the abscissa as shown in diagrams Figure 4 to 7 here. 


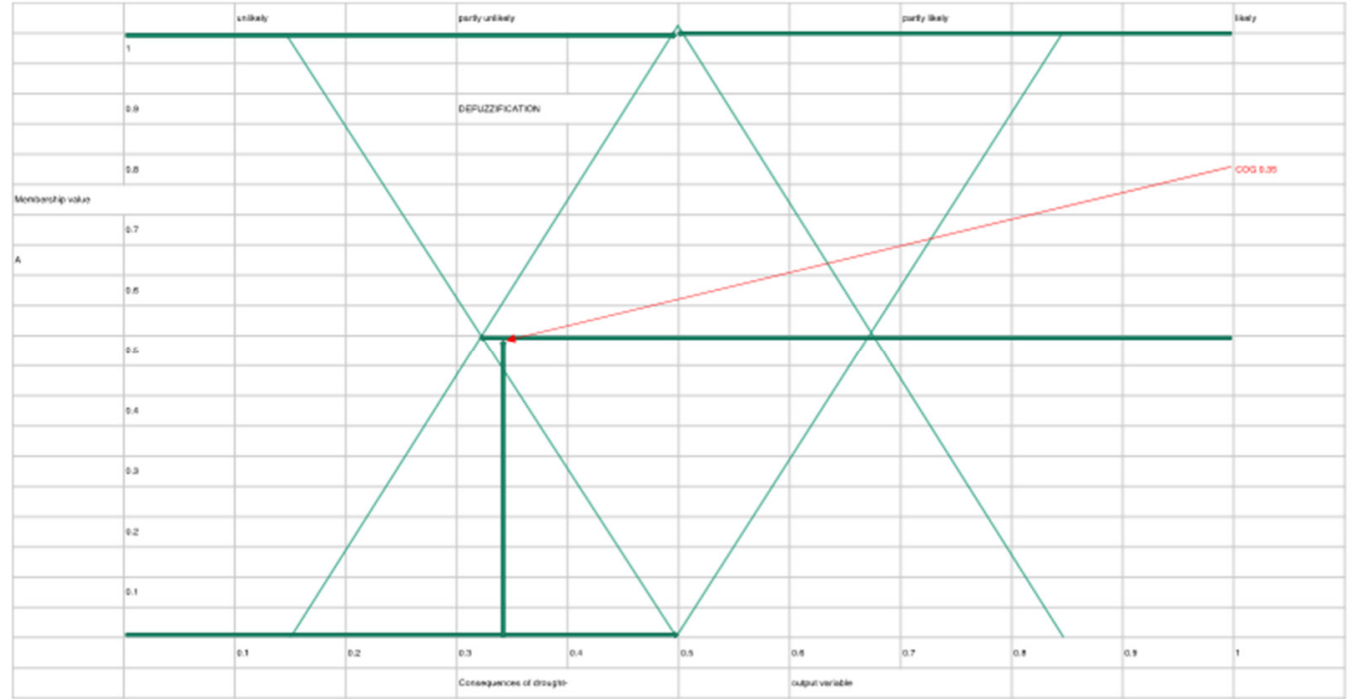

Figure 4 Defuzzification of the two indicators on availability of food and water

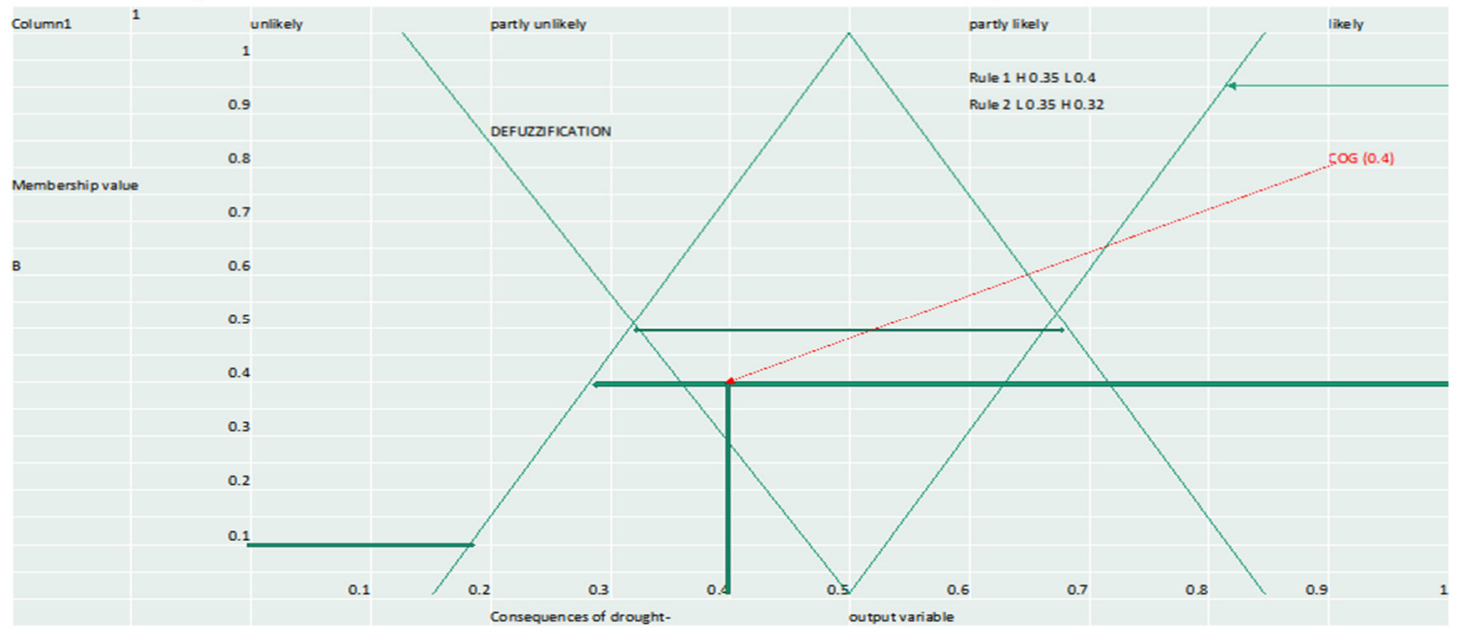

Figure 5 Defuzzification of two indicators of food production and charcoal burning

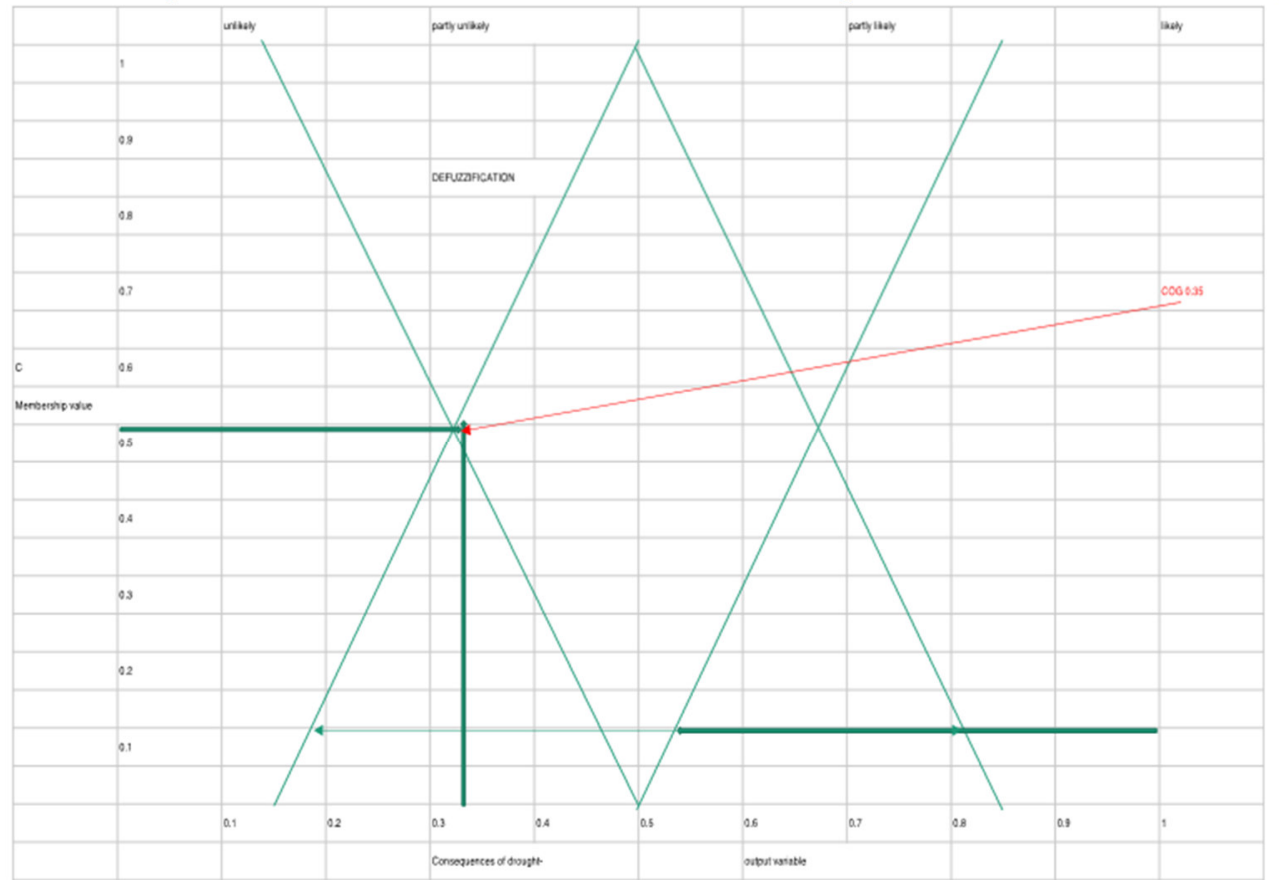

Figure 6 Defuzzification of two indicators of food aid and drinking water 


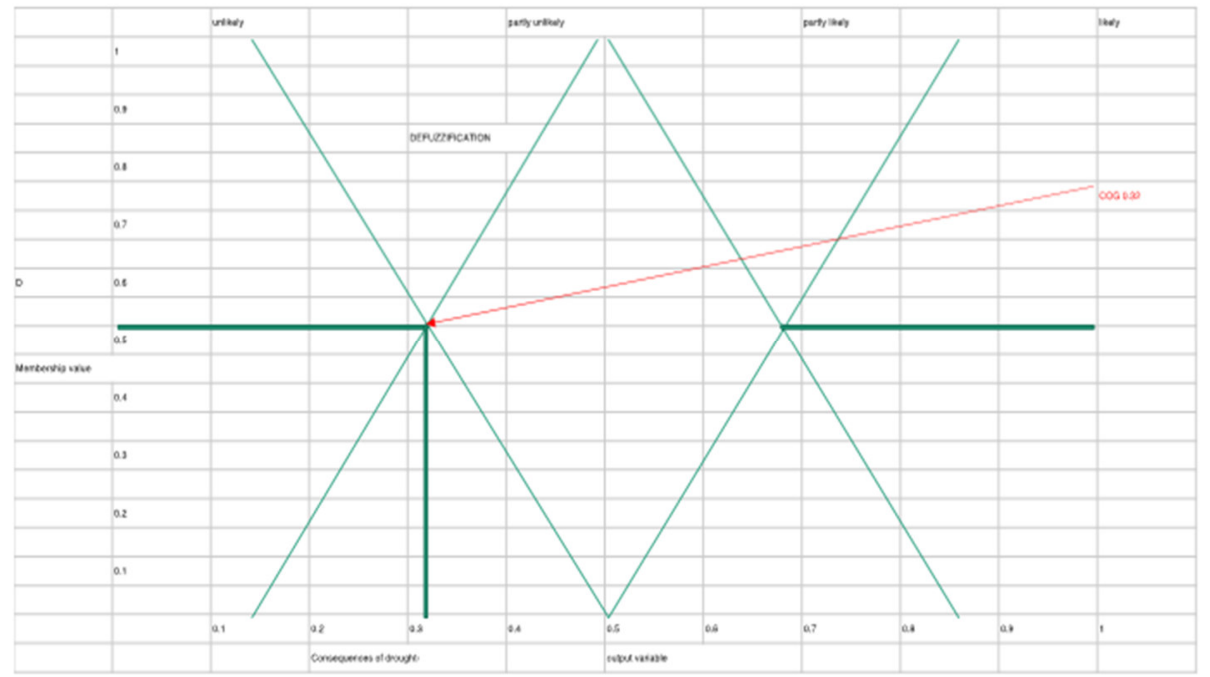

Figure 7 Defuzzification of two indicators of leaving home and being ill more often

Thus the degrees of certainty $\mu$ of the variable $\mathrm{C}$ for the four rules of inference system as analysed through defuzzification above from Figure 4 to 7 were as follows:

Rule 1: $\mu \mathrm{C}($ low $)=\min \{0.4,0.35\}=0.4$

Rule 2: $\mu \mathrm{C}($ high $)=\min \{0.32,0.35\}=0.35$

Rule 3: $\mu \mathrm{C}($ medium $)=\min \{0.4,0.35\}=0.35$

Rule 4: $\mu \mathrm{C}($ medium $)=\min \{0.33,0.32\}=0.3$

Out of the many methods available for analysis the researcher chose the Centre of gravity for the analysis for the final analysis. This required a defuzzification diagram with membership functions for every category of the output variable. In this case the degree of certainty of each variable was represented by the area it covered of the corresponding membership function. Figure 8 below is showing the final value as done through defuzzification:

Defuzzification- Centre of Gravity

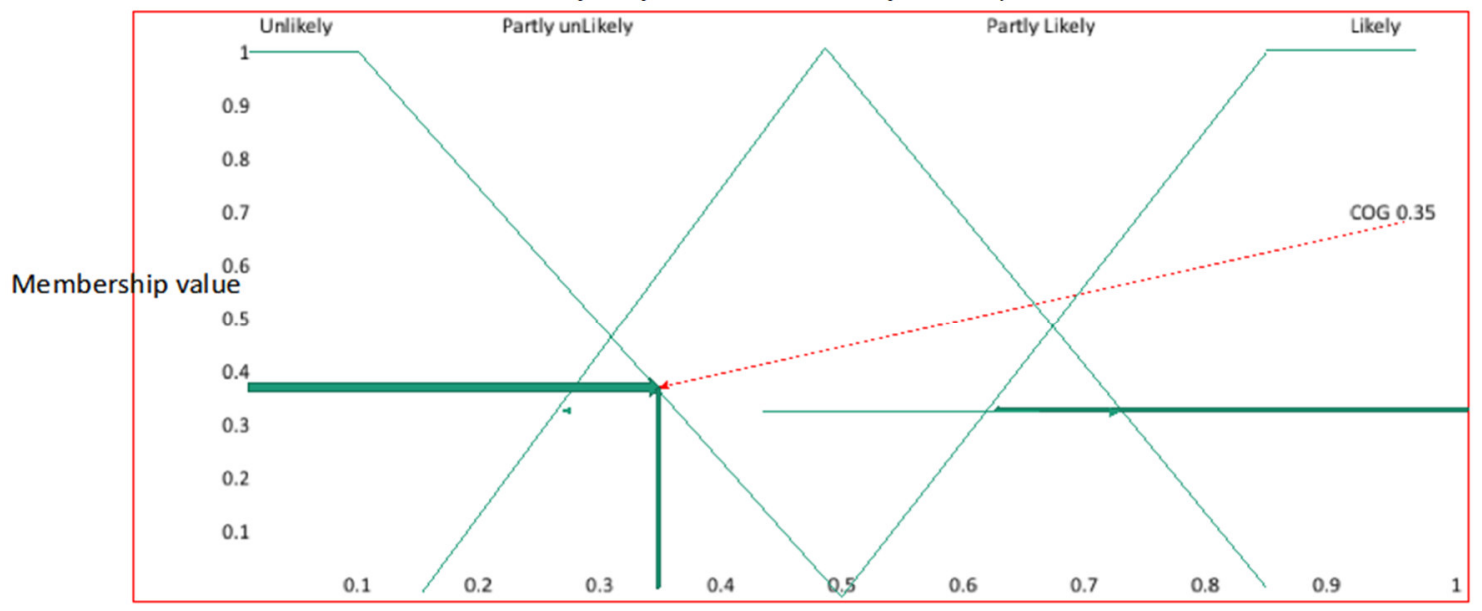

Consequences of drought

Figure 8 Negative consequences of drought for Kinakomba Ward

The Centre of gravity of a trapezoid is also calculated using this formula

$$
x=\frac{b+2 a}{3(a+b)} h
$$

The final value of the output variable, according to the centre of gravity of the joined area projected onto the abscissa, is approximately 0.35 . This implies a category of 'Partly likely' and "Partly unlikely" for the output variable namely the negative consequences of drought. With this approach the results tended to cluster towards the middle of the defuzzification diagram and variance was smoothed. Also since the centre of gravity (COG) is based on the computation of areas, the centre of an area cannot reach the extremes of the membership functions thus never tends to take values of 0 or 1 .

3.4 Results from DrinC software

The researcher analysed the Reconnaissance Drought Index, Streamflow Drought Index, Standardised 
Precipitation Index, Precipitation Deciles and Potential evapotranspiration for Kinakomba Ward for 35 years ranging from 1980 to 2015 as Table 10 shows. With the aid of SDI it was possible to know when the drought was most severe and when it was mild. Classes of hydrological drought were defined for SDI in the same way as the meteorological drought indices of SPI and RDI (Tigkas et al. 2015). These classes were rated from 0 meaning no drought at all to 4 extreme drought. The results are presented per year.

Table 10 Meteorological Data from 1980 to 2015 for Kinakomba Ward calculated using DrinC

\section{Deciles}

SPI

RDI

SDI

\begin{tabular}{|c|c|c|c|c|}
\hline $1980-81$ & 8 & 0.39 & 1.54 & 0.29 \\
\hline $1981-82$ & 5 & 0.22 & -0.77 & -1.2 \\
\hline $1982-83$ & 2 & -0.66 & -1.8 & -99 \\
\hline $1983-84$ & 4 & 0.16 & 1.81 & -99 \\
\hline $1984-85$ & 3 & -0.08 & -0.38 & -99 \\
\hline $1985-86$ & 6 & 0.24 & -0.86 & -1.1 \\
\hline $1986-87$ & 4 & 0.15 & -1.14 & -99 \\
\hline $1987-88$ & 10 & 0.5 & -0.8 & 1.1 \\
\hline $1988-89$ & 6 & 0.29 & -0.19 & -99 \\
\hline $1989-90$ & 3 & 0.07 & -99 & -99 \\
\hline $1990-91$ & 5 & 0.23 & -0.98 & -1.15 \\
\hline $1991-92$ & 8 & 0.38 & -1.16 & 0.18 \\
\hline $1992-93$ & 7 & 0.35 & -0.68 & -0.38 \\
\hline 1993-94 & 7 & 0.32 & -99 & -0.44 \\
\hline $1994-95$ & 8 & 0.36 & -99 & 0.07 \\
\hline $1995-96$ & 9 & 0.39 & -1 & 0.32 \\
\hline 1996-97 & 5 & 0.21 & -99 & -99 \\
\hline $1997-98$ & 6 & 0.24 & -99 & -99 \\
\hline $1998-99$ & 7 & 0.3 & -0.79 & -0.51 \\
\hline $1999-00$ & 4 & 0.17 & 2.36 & -1.75 \\
\hline $2000-01$ & 6 & 0.24 & -0.77 & -1.12 \\
\hline 2001-02 & 9 & 0.42 & -1.01 & 0.57 \\
\hline $2002-03$ & 8 & 0.37 & -1.13 & 0.04 \\
\hline 2003-04 & 3 & -0.03 & -1.6 & -99 \\
\hline 2004-05 & 10 & 0.53 & -0.36 & 1.46 \\
\hline $2005-06$ & 10 & 0.44 & -0.2 & 0.6 \\
\hline 2006-07 & 10 & 0.65 & 0.49 & 2.37 \\
\hline $2007-08$ & 9 & 0.43 & 0.69 & -0.28 \\
\hline 2008-09 & 2 & -0.16 & 0.84 & -99 \\
\hline 2009-10 & 2 & -0.79 & -99 & -99 \\
\hline 2010-11 & 1 & -0.89 & -99 & -99 \\
\hline 2011-12 & 1 & -5.3 & -99 & -99 \\
\hline $2012-13$ & 3 & 0.08 & -99 & -99 \\
\hline 2013-14 & 1 & -99 & -99 & -99 \\
\hline $2014-15$ & 1 & -99 & -99 & -99 \\
\hline
\end{tabular}

3.4 Results for Reconnaissance drought index (RDI)

This was developed to approach the water deficit in a more accurate way, as a sort of balance between input and output in a water system (Tsakiris and Vangelis 2005; Tsakiris et al. 2007c). The calculations were based both on cumulative precipitation $(\mathrm{P})$ and potential evapotranspiration $(\mathrm{PET})$, which were one measured $(\mathrm{P})$ and one calculated (PET) determinant. Positive values of RDIst indicated wet periods, while negative values indicated dry periods compared with the normal conditions of the area as shown in figure 11 to 14 . Drought severity was categorized in mild, moderate, severe and extreme classes with corresponding boundary values of RDIst $(-0.5$ to -1.0$),(-1.0$ to -1.5$),(-1.5$ to -2.0$)$ and $(<-2.0)$ respectively as Table 11 shows 
Table 11 History of RDIst drought in Kinakomba from 1980 to 2015 drawn using DrinC

Drought between 1980 to 2015 in Wenje

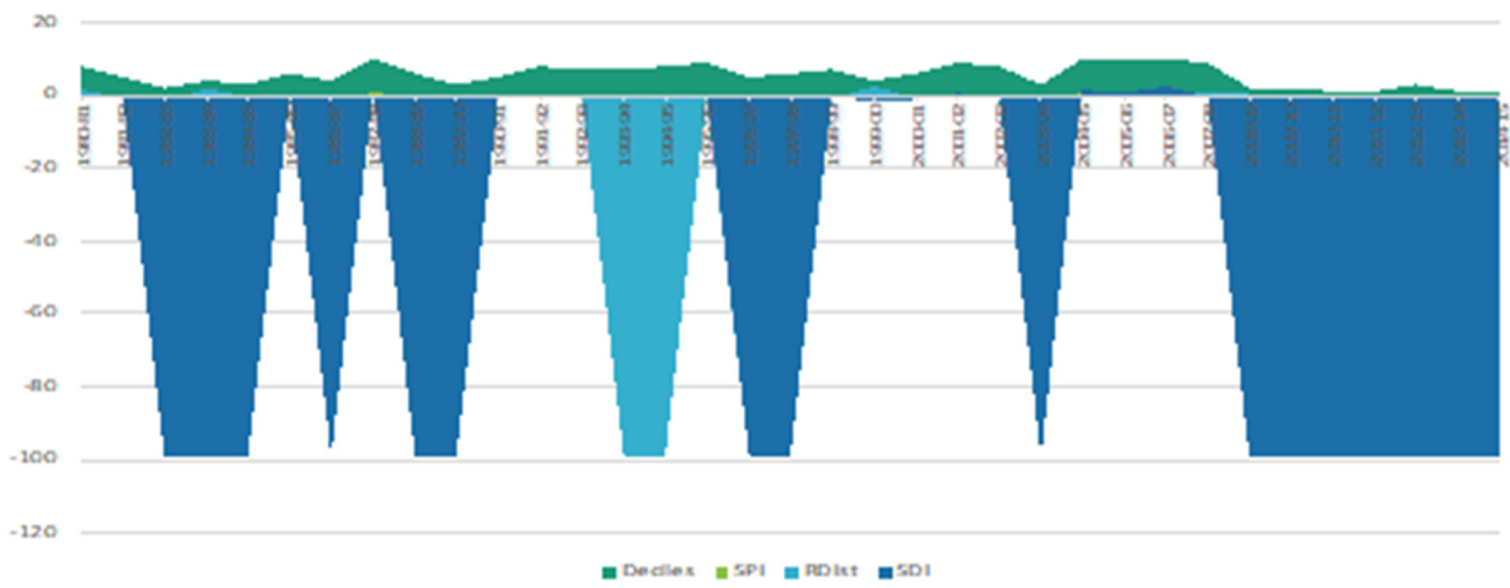

Table 12 Drought analysis for Kinakomba Ward for 35 years produced using DrinC.

Drought analysis for 35 years

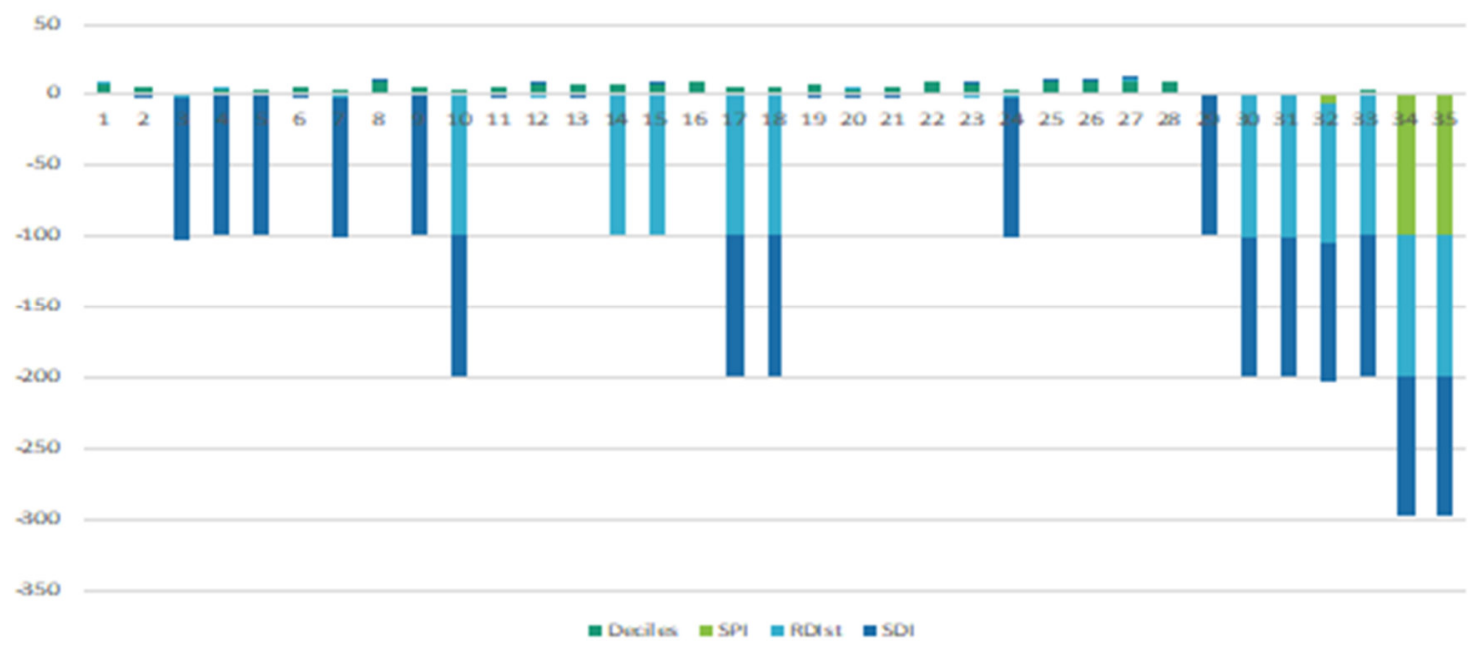

Interpretation and discussion for RDIst

Positive values of RDIst indicated wet periods, while negative values indicated dry periods

Using the RDI -WET below are the Results:

1980-81 RDIst is 1.54 meaning it was a wet year, 1983-84 was wet year with 1.81, 1999-2000 wet year with 2.36, 2006-07 wet with $0.49,2007-08$ wet with $0.69,2008-09$ wet with 0.84

Using the RDI- DRY-Severity of drought

Mild droughts $(-0.5$ to -1.0$)$

1981-82 with $-0.77,1985-86$ with $-0.86,1987-88$ with $-0.8,1988-89$ with $-0.19,1989-90$ with $-99,1990-91$ with $-0.98,1992-93$ with $-0.68,1998-99$ with $-0.79,2000-01$ with -0.77 .

Moderate Droughts (-1.0 to -1.5$)$

1986-87 with $-1.14,1991-92$ with $-1.16,1995-96$ with $-1,2001-02$ with $-1.01,2002-03$ with -1.13 ,

Severe Droughts (-1.5- to -2$)$

1982-83 with -1.8, 2003-4 with -1.6

\section{Result observations:}

1. Between 1982 to 1985 a period of three years there was mild drought. Between 1986 to 1993 a period of seven years there was a continuous mild drought. Then between 1993 to 1998 a period of five years there was another mild drought. Then 1998 to 2001 a period of three years there was a continuous mild drought.

2. Between 1987 to 1991 a period of four years there was a moderate drought. Then between 1992 to 1995 a period of three years there was another moderate drought. The between 1996 to 2001 a period of five years there was a moderate drought. Then between 2001 to 2003 a period of two years there was a continuous mild drought. 
3. In 1982 there was a severe drought. Between 1983 to 2003 a period of 20 years there was a severe drought

4. During the entire study period of 35 years there was one form or another of drought.

\subsection{Result for Standardized precipitation index (SPI)}

The calculations for the long-term precipitation record for 35 years was fitted to a probability distribution, which was then transformed into a normal distribution so that the mean SPI for Kinakomba Ward and desired period was zero (McKee et al. 1993; Edwards and McKee 1997). The SPI was the number of standard deviations that the observed value had deviated from the long-term mean, for a normally distributed random variable as presented in Table 13.

Classification of drought conditions according to the SPI:

SPI values Classification:

2.0 or more Extremely wet

1.5 to 1.99 Very wet

1.0 to 1.49 moderately wet

-0.99 to 0.99 near normal

-1.0 to -1.49 moderately dry

-1.5 to -1.99 severely dry

-2.0 or less extremely dry

(Source: Tigkas, 2014).

Table 13 Standardized precipitation index (SPI) for 35 year in Kinakomba Ward

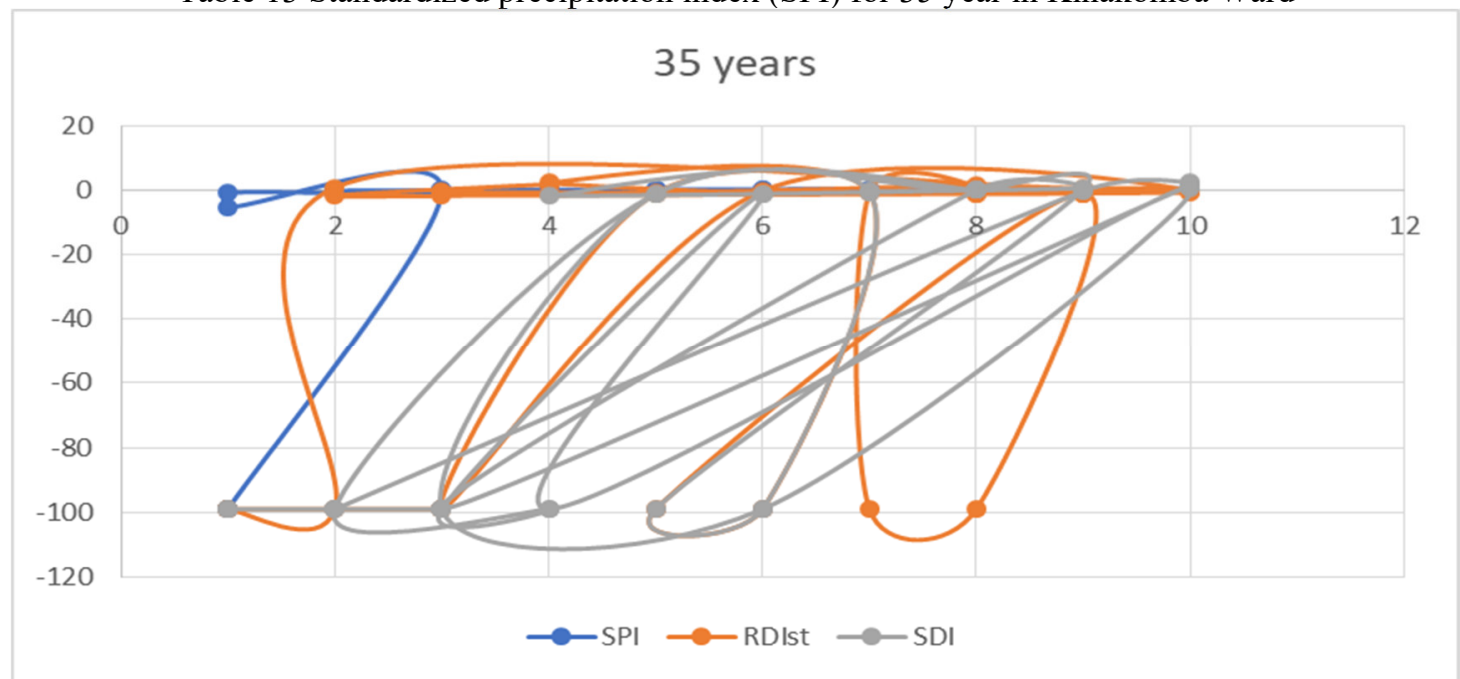

Near Normal ( -0.99 to 0.99 near normal)

1982-83 with $-0.66,1984-85$ with $-0.08,2003-04$ with $-0.03,2008-09$ with $-0.16,2009-10$ with $-0.79,2010-11$ with -0.89

-2.0 or less extremely dry

2011-12 with -5.3. Extremely dry

Results Observations:

1. Between 1982 to 1985 a period of three years there was a continuous near normal drought.

2. Between 1985 to 2003 a period of 18 years there were two near normal droughts. Between 2004 to 2008 a period of four years there were two near normal droughts and from 2008 to 2011 a period of three years there was a continuous near normal drought

3. Then Between 2011 and 2012 there was an extreme drought

Hydrological drought using SDI- 0 Non-drought SDI $\geq 0.0, \quad 1$ Mild drought $-1.0 \leq$ SDI $<0.0,2$ Moderate drought $-1.5 \leq \mathrm{SDI}<-1.0, \quad 3$ Severe drought $-2.0 \leq \mathrm{SDI}<-1.5, \quad 4$ Extreme drought SDI $<-2$.

0 Non-drought $\mathrm{SDI} \geq 0.0$

1. Mild drought $(-1.0 \leq \mathrm{SDI}<0.0)$

1992-93 with $-0.38,1993-94$ with $-0.44,1998-99$ with $-0.55,2007-08$ with -0.28

2. Moderate drought $(-1.5 \leq \mathrm{SDI}<-1.0)$

1981-82 with $-1.2,1985-86-1.1,1990-91-1.15,2000-01$ with -1.12

3. Severe drought $(-2.0 \leq \mathrm{SDI}<-1.5)$

1999-0 ith -1.75

4. Extreme drought SDI $<-2$. 
Table 14 Hydrological drought using SDI and Deciles in Kinakomba Ward for 35 years

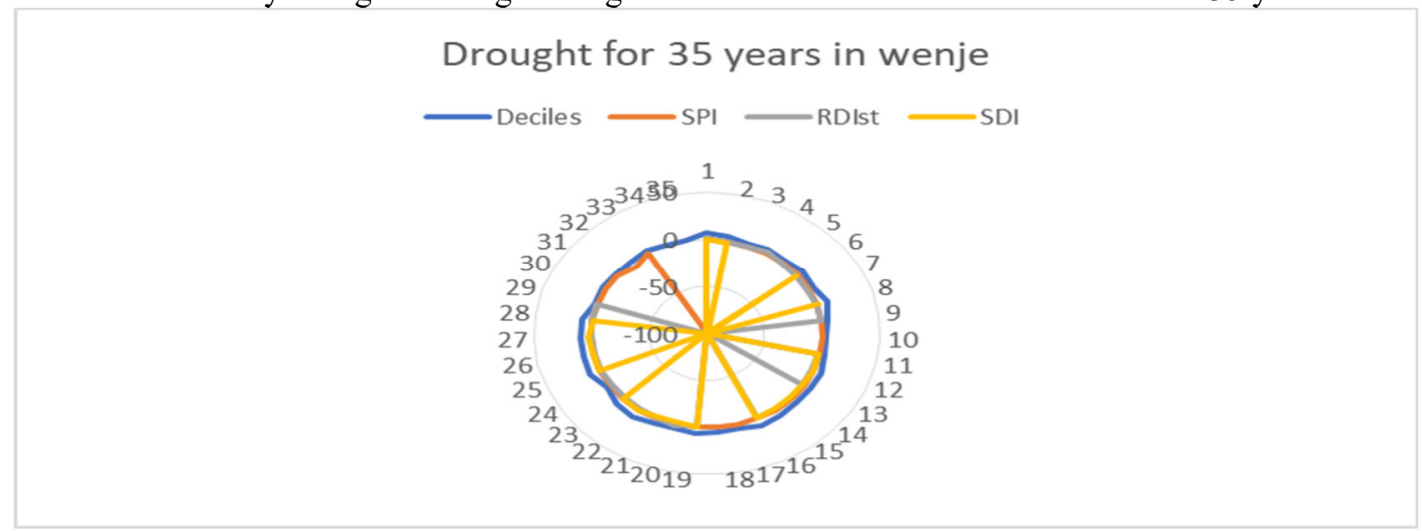

3.6 Precipitation Deciles Results

The researcher grouped the deciles into five classes as shown in Table11. The drought ended in two ways first when the precipitation measured during the past month already placed the 3-month total in or above the fourth decile, and secondly when the precipitation total for the past 3 months was in or above the eighth decile.

Deciles 1-2: lowest 20\%. Much below normal

Decile 3-4: Next lowest 20\%. Below normal

Decile 5-6: Middle Near Normal

Decile 7-8 Next Highest Above Normal

Deciles 9-10 Highest Much above normal (Source: Tigkas 2014).

Deciles 1-2: lowest 20\%

1982-83 with 2, 2008-09 with 2, 2009-10 with 2, 2010-11 with 1, 2011-12 with $\mathbf{1}$,

Table 15 Deciles for Kinakomba Ward for the last 30 years with thresholds analysed using DrinC

Deciles:

$1980-1981$

$1981-1982$

$1982-1983$

$1983-1984$

$1984-1985$

1985 - 1986

1986 - 1987

1987 - 1988

1988 - 1989

$1989-1990$

1990 - 1991

1991 - 1992

$1992-1993$

1993 - 1994

1994 - 1995

1995 - 1996

1996 - 1997

1997 - 1998

1998 - 1999

$1999-2000$

2000 - 2001

$2001-2002$

$2002-2003$

$2003-2004$

2004 - 2005

2005 - 2006

$2006-2007$

2007 - 2008

2008 - 2009

$2009-2010$
Thresholds

$\begin{array}{rr}10 \% & 131.5 \\ 20 \% & 177.3 \\ 30 \% & 274.6 \\ 40 \% & 301.9 \\ 50 \% & 314.0 \\ 60 \% & 341.1 \\ 70 \% & 394.5 \\ 80 \% & 430.5 \\ 90 \% & 544.3 \\ 100 \% & 950.4\end{array}$




\section{Results Observations:}

1. The area was under drought conditions with deciles of 2 for the lowest $20 \%$ in the 2008-09 year, 200910 year 2010-11 year and 2011-12 year making a total of 4 years under these drought conditions.

\section{Deciles for 30 year period}

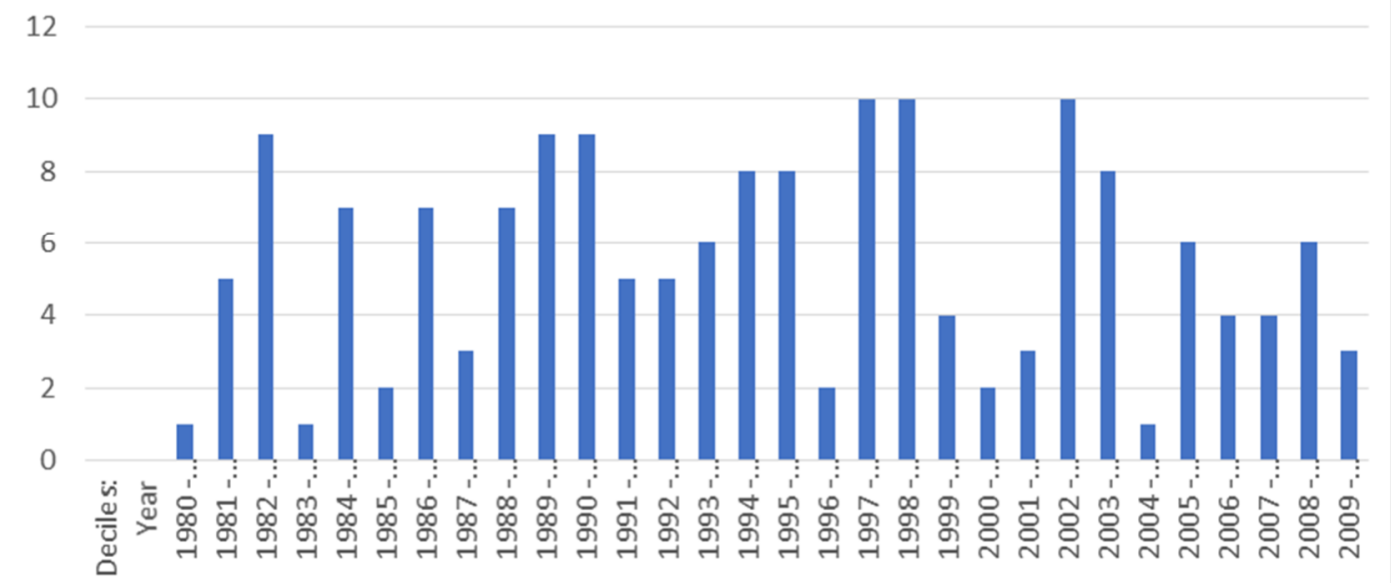

Figure 9 Deciles for 30 years in Kinakomba Ward and surrounding areas

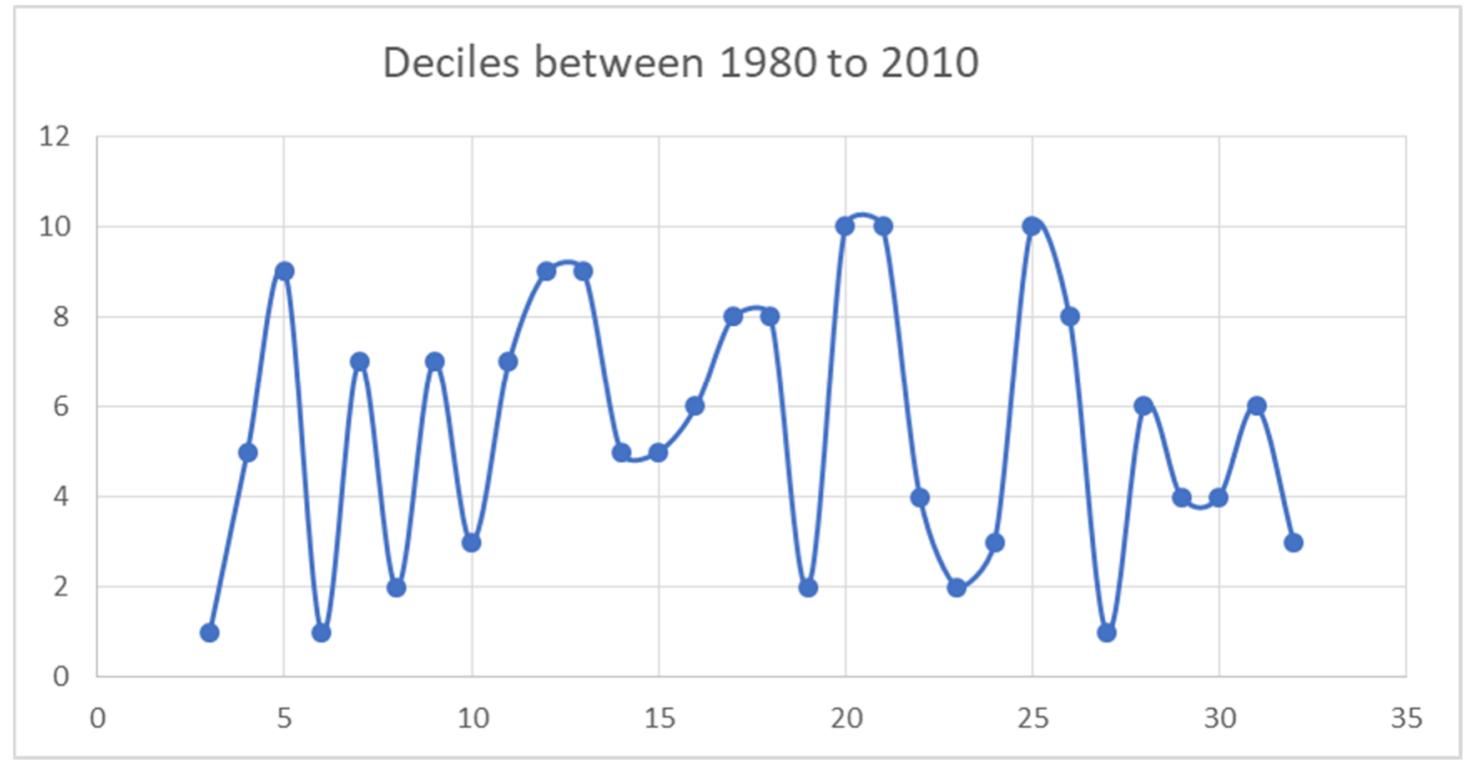

Figure 10 Deciles thresholds in Kinakomba Ward and surrounding areas 


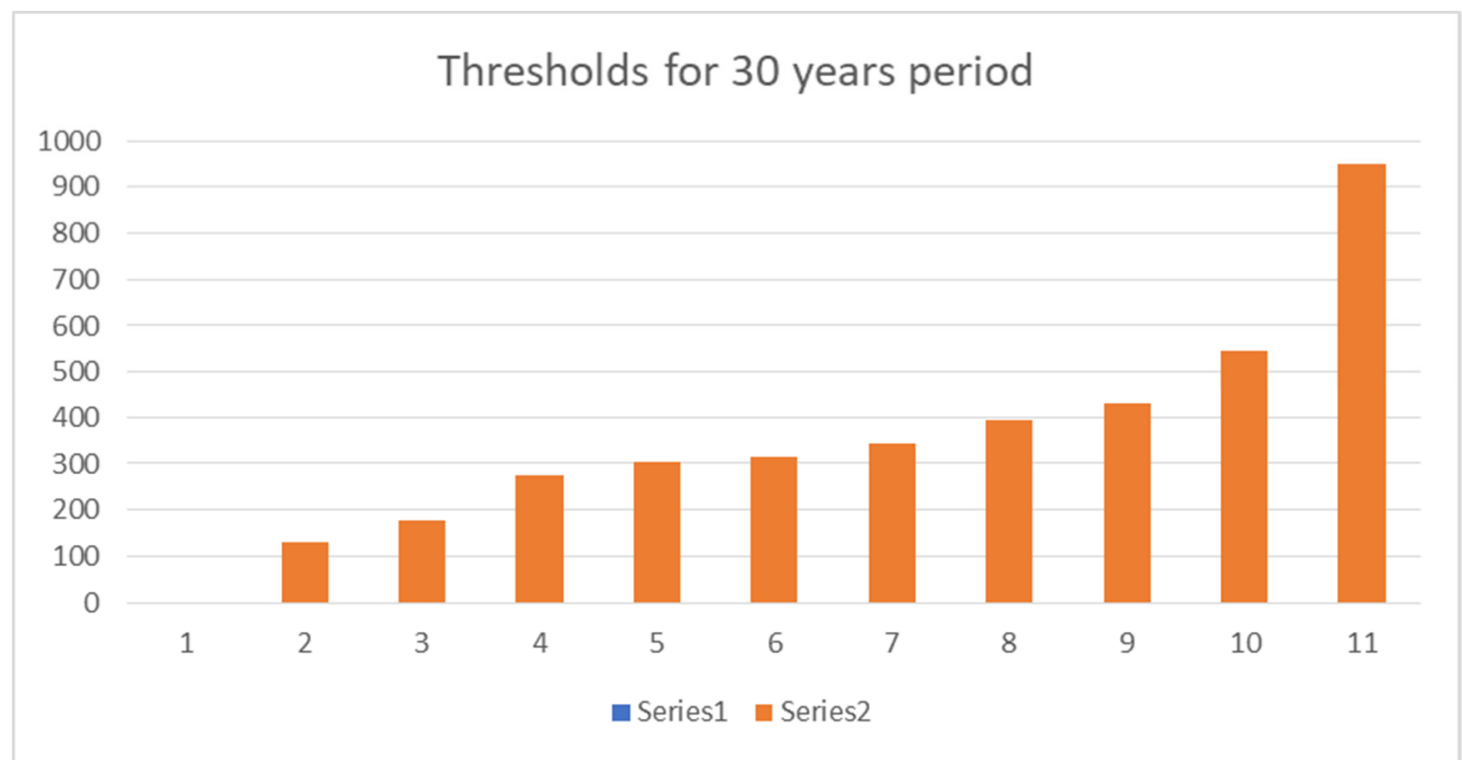

Figure 11 Thresholds for 30 years period in Kinakomba Ward and surrounding areas

3.7 Defuzzification Results of all the indices for the DrinC data for 35 years

Using defuzzification through the Centre of gravity method the researcher established a single index for exposure for the entire study period for Kinakomba Ward as 0.45 indicating the need for mitigation and adaptation measures to equip the smallholder farmers to cope with the cyclic and vicious droughts impacts that have led to serious food and nutritional insecurity with irreversible harm to human and livestock in the area. The researcher used the AND conditions, where the mathematically appropriate set operation was an intersection, computed as the minimum of the two membership values. Thus, the degrees of certainty $\mu$ of the variable $\mathrm{C}$ for the four rules of the inference system was as follows:

Rules

Rule $1: \mu \mathrm{C}($ low $)=\min \{0.3,0.5\}=0.5$

Rule 2: $\mu \mathrm{C}$ (high) $=\min \{0.8,0.85\}=0.8$

Rule 3: $\mu \mathrm{C}($ medium $)=\min \{0.3,0.85\}=0.85$

Rule 4: $\mu \mathrm{C}($ medium $)=\min \{0.8,0.5\}=0.8$

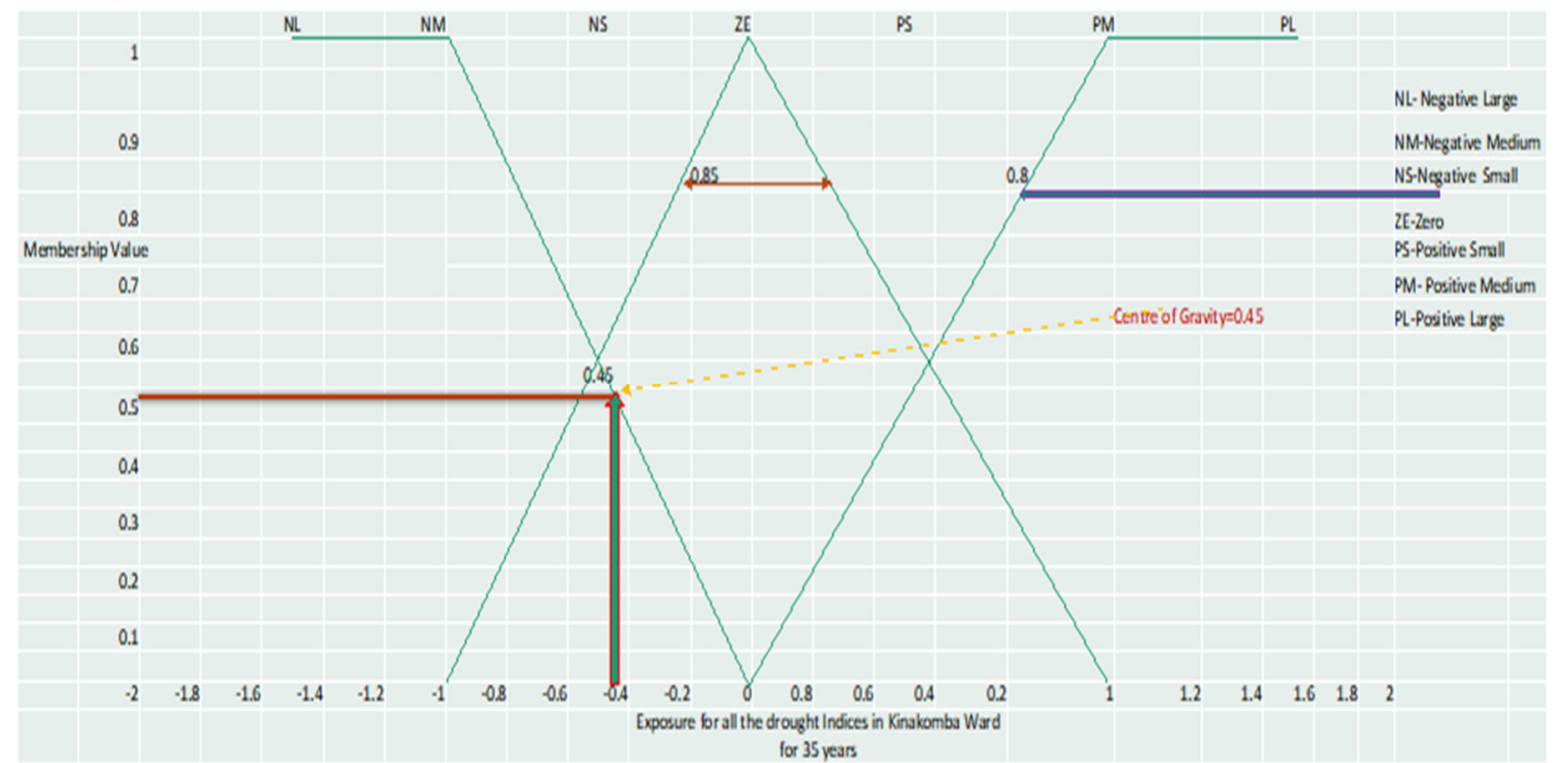

Figure 12 Centre of Gravity from Defuzzification method

Interpretation of the Results

From the available data in there was moderate drought in 1985 to 1986 with SDI reading -1.1. Then in 1990 to 1991 moderate drought with SDI reading -1.15. From 1999 to 2000 there was severe drought with SDI reading 1.75 (Table 2) and according to the respondents this was after the El Nino rains that had come from 1997 to 1998. 
Then from 2000 to 2001 there was another moderate drought with SDI reading -1.12. Between 2011 to 2012 there was extreme drought, one of the worst in the history of Kenya with SPI reading -5.3 (Table 10 to 14).

Also from this data drought frequency the researcher deduced that from 1985 to 1990 a period of five years moderate drought was experienced. Then between 1985 to 1999 a period of 14 years a severe drought was experienced. But between 2000 and 2011 a period of 11 years two severe droughts occurred with the second one being an extreme drought pointing to the finding that the periods between occurrence of drought are reducing and on the same note that droughts are moving from severe to extreme within shorter periods leaving the farmers depending on rain fed agriculture extremely vulnerable to climatic shocks risking longer hunger years with unpredictable frequency.

\subsection{Testing for Hypothesis Results}

Degrees of Freedom (DF) was equal to the number of levels (k) of the categorical variable minus $1: \mathrm{DF}=\mathrm{k}-1$. In Kinakomba Ward it was 3-1=2

The expected frequency counts at each level of the categorical variable are equal to the sample size times the hypothesized proportion from the null hypothesis.

$$
\mathrm{E}_{\mathrm{i}}=n \mathrm{p}_{\mathrm{i}}
$$

Where $\mathrm{E}_{\mathrm{i}}$ is the expected frequency count for the $i$ th level of the categorical variable, $\mathrm{n}$ is the total sample size, and $\mathrm{p}_{\mathrm{i}}$ is the hypothesized proportion of observations in level $i$. In this Study:

$$
\mathrm{E}_{1}=390 * 0.477(186.03) \quad \mathrm{E}_{2}=390 * 0.136(53.04) \mathrm{E}_{3}=390 * 0.387(150.93)
$$

Our farms will not be able to yield any harvests as shown in Table 16

Table 16 The observed and the expected frequencies

\begin{tabular}{|ll|l|l|}
\hline & Frequency & Percent \\
\hline Valid & likely & 151 & 38.7 \\
& partly likely and partly & 53 & 13.6 \\
& unlikely & 186 & 47.7 \\
unlikely & 390 & 100.0 \\
& Total & & \\
\hline
\end{tabular}

The test statistic is a chi-square random variable $\left(\mathrm{X}^{2}\right)$ defined by the following equation:

$$
\mathrm{X}^{2}=\Sigma\left[\left(\mathrm{O}_{\mathrm{i}}-\mathrm{E}_{\mathrm{i}}\right)^{2} / \mathrm{E}_{\mathrm{i}}\right]
$$

Where $\mathrm{O}_{\mathrm{i}}$ is the observed frequency count for the $i$ th level of the categorical variable, and $\mathrm{E}_{\mathrm{i}}$ is the expected frequency count for the $i$ th level of the categorical variable.

$\mathrm{X}^{2}=\Sigma\left[\left(\mathrm{O}_{\mathrm{i}}-\mathrm{E}_{\mathrm{i}}\right)^{2} / \mathrm{E}_{\mathrm{i}}\right]$

$\mathrm{X}^{2}=\left[(186-186.03)^{2} / 186.03\right]+\left[(53-53.04)^{2} / 53.04\right]+\left[(151-150.93)^{2} / 150.93\right]$

$\mathrm{X}^{2}=\left[(-0.03)^{2} / 186.03\right]+\left[(0.04)^{2} / 53.04\right]+\left[(0.07)^{2 / 150.93]}\right.$

$=0.000004+0.000030+0.000032=0.000066$

where DF is the degrees of freedom, $\mathrm{k}$ is the number of levels of the categorical variable, $\mathrm{n}$ is the number of observations in the sample, $\mathrm{E}_{\mathrm{i}}$ is the expected frequency count for level $\mathrm{i}, \mathrm{O}_{\mathrm{i}}$ is the observed frequency count for level $\mathrm{i}$, and $\mathrm{X}^{2}$ is the chi-square test statistic.

The P-value is the probability that a chi-square statistic having 2 degrees of freedom is more extreme than 0.995 . Using the Chi-square Distribution Calculator to find $\mathrm{P}\left(\mathrm{X}^{2}>0.995\right)=0.000066$.

Test Statistic

Table 17 Chi-square test

\begin{tabular}{|l|l|}
\hline \multicolumn{1}{|l|}{} & Table 17 Chi-square test \\
\hline Chi-Square & $000^{\mathrm{a}}$ \\
df & 2 \\
Asymp. Sig. & 1.000 \\
Monte Carlo Sig. & $1.000^{\mathrm{b}}$ \\
& \\
99\% lower bound & 1.000 \\
Interval upper bound be able to yield any harvest & 1.000 \\
\hline
\end{tabular}

Interpretation of the Results

Since the P-value (0.000066) is less than the significance level $(0.01)$, the researcher could not accept the null hypothesis. This approach was appropriate because the sampling method was simple random sampling, the variable under study was categorical, and each level of the categorical variable had an expected frequency count 
of at least 5

\section{Conclusions}

The researcher calculated Deciles, RDI, SPI and SDI using DrinC to the sample area. Based on the RDI values, severe droughts took long to come and they were unpredictable like between 1983 to 2003 . Secondly during the study period mild droughts took a continuous seven years between 1986 to 1993, then another continuous five years between 1993 to 1998 followed by another continuous three years between 1998 to 2001. These were unpredictable patterns that became a challenge to the smallholder farmers for them to plan for their agricultural activities as they had been used to in previous years while depending on rain fed agriculture. Farmers were earlier used to long and short rains only.

Based on the SPI values the researcher established that there was a continuous near normal drought for a period of three years between 1982 to 1985 . Then there was another two periods of near normal droughts for a period of 18 years between 1985 to 2003. Again there were two near normal droughts for a period of four years from 2004 to 2008 and another period of three years of continuous near normal drought from 2008 to 2011 a period that culminated with an extreme drought between 2011 and 2012.

Based on SDI the researcher established that there was mild drought from 1992 to 1994 then followed a break of four years with another mild drought starting in 1998 to 1999 . That was followed by another mild drought after eight years between 2007 to 2008 but in between 1999 to 2000 there was severe drought. This makes drought trends highly unpredictable striking and impacting smallholder farmers in longer continuous periods and therefore breaking their survival mechanisms and capacities leaving them bear and under exposure. This also drives them to hopelessness in their food production while depending on rain fed agriculture.

Based on the Deciles values the researcher established that the study area was under drought conditions with deciles of 2 for the lowest $20 \%$ for a period of four years between 2008 to 2012. Throughout the study period of 35 years there were droughts of different intensity and magnitude. Furthermore in a period of eleven years between 2000 and 2011 two severe droughts occurred with the second one being an extreme drought pointing to the finding;

That the periods between occurrence of extreme droughts were reducing and at the same time that droughts were moving from being severe to being extreme within shorter periods of time leaving smallholder farmers who depend on rain fed agriculture in high exposures and risks as well as experiencing longer hunger periods with severe implications on their food and nutritional security for the vast populations in the study area.

Thus using all the values of drought indices the researcher established the categories of drought for the study period in the area. Using defuzzification through the Centre of gravity method the researcher established a single index for exposure for the entire study period for Kinakomba Ward as 0.45 indicating the need for mitigation and adaptation measures to equip the smallholder farmers to cope with the cyclic and vicious droughts impacts that have led to serious food and nutritional insecurity with irreversible harm to human and livestock in the area.

The use of inference modelling and fuzzy logic approach assisted the researcher to provide new insights into susceptibility to drought in consistence with Eakin H. and Tapia B. (2008). Some of the advantages of this approach include enhancing the transparency of model assumptions. Since all the rules in an inference model must be explicitly specified, this meant that all key cause-effect relationships in the model were relatively transparent. It also provided the researcher with a tool for qualitative interpretation of numerical data. Through the fuzzy membership functions, numerical data were qualitatively interpreted. This translation into linguistic terms facilitated the use of linguistic, qualitative inference models for quantification. Documenting the parameters and sources of information for the membership functions made the procedure more transparent. The approach enabled the researcher to produce quantitative results through qualitative modelling. Since much of the information available to vulnerability assessments is qualitative rather than quantitative, the inference modelling approach is particularly appropriate because it relies on specifying inference rules which embody qualitative knowledge. Through fuzzy logic these rules are then converted to quantitative information. Moreover the inference rules can be used to express non-linear relationships between influence factors and susceptibility.

\section{Recommendations}

The deciles index is a more useful index in assisting decision-makers to determine where financial assistance has to be provided in times of drought. The goal being to reduce exposure to extreme drought effects bringing food insecurity because the main determinant of agricultural production are the seasonal variation of temperature, precipitation and sunshine. Exposure to droughts stresses humans, crops and livestock. This study recommends that the County Government in partnership with the National Government and other stakeholders develop a comprehensive disaster risk management framework to address the drought hazards and undertake mitigation measures including reducing use of burning of fossil fuels like diesel and petrol for irrigation. Other mitigation measures would be protecting the river banks by planting trees along it so that this can enhance the sinks that will eventually trap and store the greenhouse gases that are in the atmosphere as a result of drought coping strategies like charcoal burning, reductions in methane and nitrous oxide emissions in the agricultural systems. Then through 
improved crop and grazing land management to increase soil carbon storage by restoration of cultivated soils and degraded lands, improved cultivation techniques and livestock and manure management to reduce emissions, improved nitrogen fertilizer application techniques to reduce emissions, dedicated energy crops to replace fossil fuel use and improved energy efficiency. A large proportion of the mitigation potential of agriculture arises from soil carbon sequestration, which has strong synergies with sustainable agriculture and generally reduces exposure to drought.

Adaptation strategies for exposure to drought include using scarce water resources more efficiently, Changing planting dates, Planting different varieties or crop species, Development and promotion of alternative crops, developing new drought and heat-resistant varieties, use of intercropping, use of sustainable fertilizer and tillage practices which improves soil drainage, improved crop residue and weed management like use of water harvesting techniques, better pest and disease control for crops; and implementing new or improving existing irrigation systems to reducing water leakage, soil moisture conservation like mulching. Using solar energy for irrigation and gravity instead of fossil fuels. Improving livestock management practices like providing housing and shade, to heat-tolerant breeds like browsers, change in stocking rate, altered grazing and rotation of pasture all these are good adaptation measures. Others include using agroecological approaches and use of agroforestry practices and development of early-warning systems and protection measures against drought. Reforestation along the river bank can provide mitigation and adaptation and have substantial co-benefits in terms of employment, income generation, biodiversity and watershed conservation, renewable energy supply and poverty alleviation.

\section{REFERENCES}

Acosta-Michlik L, Kavi-Kumar K, Klein R, Campe S (2008) Application of fuzzy models to assess susceptibility to drought from a socio-economic perspective. Reg Environ Change. XX

Alcamo J, Acosta-Michlik L, Carius A, Eierdanz F, Klein R, Kro“mker D, Ta“nzler D (2008) A new approach to quantifying and comparing vulnerability to drought. Reg Environ Change. XX

Alcamo J, Acosta-Michlik E, Carius A, Eierdanz F, Klein R, Kro“mker D, Tänzler D (2005) A new approach to the assessment of vulnerability to drought. In: Proceedings of Final Symposium of the German Climate Research Programme (DEKLIM). Leipzig

Aliev R, Bondif KW, Aliew F (2000) Soft Computing: einegrund legend Einführung. Berlin

Birkmann, J., Welle, T., Krause, D., Wolfertz, J., Suarez, D.C. and Setiadi, N. (2011) World Risk Index: Concept and Results, Welt Risiko Bericht (Ed.), pp.S.13-43, Bündnis EntwicklungHilft, Berlin.

Birkmann J, Garschagen M, Mucke P, Schauder A, Seibert T, Welle T, Rhyner J, Kohler S, Loster T, Reinhard D, Matuschke I (2014) World Risk Report 2014. Bündnis EntwicklungHilft and UNUEHS doi:10.1126/science.79.2037.38. PMID 17813446.

Bollin C, Hidajat R (2006) Community-based disaster risk index: pilot implementation in Indonesia, towards disaster resilient societies. In: Birkmann J (ed) Measuring vulnerability to natural hazards. UNU-Press, Tokyo, New York, Paris

Bothe H-H (1998) Neuro-Fuzzy-Method en. Einführung in Theorie und Anwendungen, Berlin

Cronbach LJ (1951). "Coefficient alpha and the internal structure of tests". Psychometrika 16 (3): $297-334$.

Dai A (2011) Drought under global warming A review. WIREs climate change, global circulation 2: 45-65.

Eakin, H. and Tapia, B. (2008) Insights into the composition of household vulnerability from multi criteria decision analysis. Global Environmental Change, 18, 112- 127. doi:10.1016/j.gloenvcha.2007.09.001

Edwards D.C. and McKee T.B. (1997) Characteristics of 20th century drought in the United States at multiple time scales. Climatology. Report number 97-2, Colorado State University, Fort Collins, Colorado

Garschagen M., (2014) Risky change? Vulnerability and adaptation between climate change and transformation dynamics in Can Tho City, Vietnam. Steiner 15, Stuttgart

Gibbs WJ, Meher JV (1967) Rainfall Deciles as drought indicators. Bureau of Meteorology, Bulletin No. 4, Commonwealth of Austarlia, Melbbourne Austria.

IPCC. 2007. Summary for Policymakers. In: Parry ML, Canziani OF, Palutikof JP, Linden PJ, Hanson CE, editors. Climate change 2007: impacts, adaptation and vulnerability. Contribution of working group II to the fourth assessment report of the Intergovernmental panel on climate change. Cambridge (UK): Cambridge University Press.

IPCC, (2010),"Assessment of adaptation practices, options, constraints and capacity" (PDF). Archived (PDF) from the original on 27 August 2010. Retrieved 2010-08-29.

IPCC (2012) Summary for Policymakers. Managing the Risks of Extreme Events and Disasters to Advance Climate Change Adaptation, Field, C.B., Barros, V., Stocker, T.F., Qin, D., Dokken, D.J., Ebi, K.L., Mastrandrea, M.D., Mach, K.J., Plattner, G-K., Allen, S.K.,Tignor, M. and Midgley and, P.M. et al. (Eds.), A Special Report of Working Groups I and II of the Intergovernmental Panel on Climate Change, pp.1-19, Cambridge University Press, Cambridge, UK, and New York.

IPCC (2013) Climate change 2013: the physical science basis. Fifth assessment report of IPCC, Summary for 
policy makers.

Intergovernmental Panel on CC (2001) CC 2001: Impacts, adaptation and vulnerability. 3rd Assessment Report of the Intergovernmental Panel on CC, Adaptation to CC in the Context of Sustainable Development and Equity, Chapter 18, Cambridge University Press, Cambridge, 877-912.

Kangas AS, Kangas J (2004) Probability, possibility and evidence: approaches to consider risk and uncertainty in forestry decision analysis. For Policy Econ 6(2):169-188. doi:10.1016/S1389-9341(02)00083-7

Kininmonth W.R., Voice M.E., Beard G.S., de Hoedt G.C. and Mullen C.E (2000) Australian climate services for drought management. In D.A. Wilhite (ed.) Drought, a global assessment. Routledge, pp.210-222

Klein, R.J.T. (2004) Approaches, methods and tools for cc impact, vulnerability and adaptation assessment. InSession Workshop on Impacts of, and Vulnerability and Adaptation to CC, 21 st Session of the UNFCCC Subsidiary Body for Scientific and Technical Advice, Buenos Ai-res, 8 December 2004

Kloos J, Asare-Kyei D, Pardoe J, Renaud FG., (2015): Towards the development of an adapted multi-hazard risk assessment framework for the West Sudanian Savanna Zone. UNU- EHS Publication 11:4-26

Kothari C. R (2004), Research Methodology, Methods and Techniques, Second Revised Edition 2004, New Age International (P) Ltd., Publishers, India at Dharmesh Printers, Delhi.

Kro“mker D, Eierdanz F, Stolberg A (2008) who is susceptible and why? An agent-based approach to assessing vulnerability to drought. Regional Environmental Change. Volume XX

Levin, S., Xepapadeas, T., Crépin, A., Norberg, J., De Zeeuw, A., Folke, C., Hughes, T., Arrow, K., Barrett, S., Daily, G., Ehrlich, P., Kautsky, N., Mäler, K., Polasky, S.,

Mackay DS, Robinson VB (2000) A multiple criteria decision support system for testing integrated environmental models. Fuzzy Sets Syst 113:53-67.doi:10.1016/S0165-0114 (99)00012-3

Mansur AV, Brondizio ES, Roy S, Hetrick S, Vogt N, Newton A.,(2016) An assessment of urban vulnerability in the Amazon Delta and Estuary: a multi-criterion index of flood exposure, socio-economic conditions and infrastructure. Sust Sci. doi: 10.1007/s11625-016-0355-7

McGinnis, M.D., \& Ostrom, E. (2014).Social ecological system framework: initial changes and continuing challenges. Ecology and Society, 19 (2) (30), 06387190230.

McKee, T. B.; Doesken, N. J.; Kleist, J. 1993. The relationship of drought frequency and duration to timescales. Proceedings of the 8th Conference on Applied Climatology. American Meteorological Society Boston, MA.

McKee TB, Edwards DC (1997) Characteristics of 20th century droughts in the United States at multiple time scales. Journal of atmospheric science 634: 97-92.

Mosmans A, Praet J-C, Dumont C (2002) A decision support system for the budgeting of the Belgian health care system. Eur J Oper Res 139:449-460. doi:10.1016/S0377-2217(01)00369-1

Mugenda, O.M. and Mugenda A.G., (2010).Research Method; Qualitative and Quantitative approaches. African Centre for technology studies (ACTS) press - Nairobi (Kenya)

O’Brien KL, Leichenko RM, Kelkar U, Venema HM, Aandahl G, Tompkins H, Javed A, Bhadwal S, Barg S, Nygaard L, West, J. 2004. Mapping vulnerability to multiple stressors: climate change and globalization in India. Global Environ Change. 14:303-313.doi: 10.1016/j.gloenvcha.2004.01.001

Ohl, C., Krauze, K. and GrünbüheL, C., (2007). Towards an understanding of long-term ecosystem dynamics by merging socio-economic and environmental research: Criteria for long-term socio-ecological research sites selection. Ecological Economics, 63(2- 3): 383-391.

Ostrom E.,(2007).A diagnostic approach for going beyond panaceas. Proceedings of the National Academy of Sciences 104 (39):15181-15187. http://dx.doi.org/10.1073/pnas.0702288104

Peduzzi, P., Dao, H., Herold, C. and Mouton, F. (2009) 'Assessing global exposure and vulnerability towards natural hazards: the disaster risk index’, Natural Hazards and Earth System Sciences, Vol. 9, No. 4, pp.1149-1159.

Roberts DW (1996) Modelling forest dynamics with vital attributes and fuzzy systems theory. Ecol Modell 90:161-173. doi: 10.1016/0304-3800(95)00163-8

Sebesvari Z, Renaud FG, Haas S, Tessler Z, Hagenlocher M, Kloos J, Szabo S, Tejedor A, Kuenzer C., A review of vulnerability indicators for deltaic social-ecological systems, (2016), Sustain Sci DOI $10.1007 / \mathrm{s} 11625-016-0366-4$

Silvert W (2000) Fuzzy indices of environmental conditions. Ecol Modell 130:111-119. doi:10.1016/S03043800(00)00204-0

Ta“nzler D, Carius A (2008) Assessing the susceptibility of societies to droughts: a political science perspective. Reg Environ Change. XX

Tigkas D., Vangelis H., Tsakiris G. (2014), DrinC: a software for drought analysis based on drought indices. Earth Science Informatics. Volume 8, Issue 3, pp 697-709

Troell, M., Vincent, J.R. and Walker, B., (2013). Social-ecological systems as complex adaptive systems: modelling and policy implications. Environment and Development Economics, 18(02): 111.

Tsakiris G, Vangelis H (2004) towards a drought watch system based on spatial SPI. Water Resour Manag 
$18(1): 1-12$

Tsakiris G, Vangelis H (2005) Establishing a drought index incorporating evapotranspiration. Eur Water 9/10:311

Tsakiris G, Pangalou D, Vangelis H (2007c) Regional drought assessment based on the reconnaissance drought index (RDI). Water Resource Manage 21(5):821-833

UN (United Nations), (2009): Global Assessment Report on Disaster Risk Reduction. Risk and poverty in a changing climate United Nations, Geneva

UN (United Nations), (2011): Global Assessment Report on Disaster Risk Reduction. Revealing risk, redefining development United Nations, Geneva

UN (United Nations), (2013): Global Assessment Report on Disaster Risk Reduction 2013. From Shared Risk to Shared Value: the Business Case for Disaster Risk Reduction. United Nations, Geneva 